\title{
Contiguity in episodic memory
}

\author{
M. Karl Healey ${ }^{1} \cdot$ Nicole M. Long ${ }^{2} \cdot$ Michael J. Kahana $^{3}$ \\ Published online: 21 November 2018 \\ (c) Psychonomic Society, Inc. 2018
}

\begin{abstract}
Contiguity is one of the major predictors of recall dynamics in human episodic memory. But there are many competing theories of how the memory system gives rise to contiguity. Here we provide a set of benchmark findings for which any such theory should account. These benchmarks are drawn from a review of the existing literature as well as analyses of both new and archival data. They include 34 distinct findings on how various factors including individual and group differences, task parameters, and type of stimuli influence the magnitude of the contiguity effect. We will see that contiguity is observed in a range of tasks including recognition, paired associates, and autobiographical recall and across a range of time scales including minutes, days, weeks, and years. The broad pattern of data point toward a theory in which contiguity arises from fundamental memory mechanisms that encode and search an approximately time scale invariant representation of temporal distance.
\end{abstract}

Keywords Episodic memory $\cdot$ Free recall $\cdot$ Recognition $\cdot$ Paired associates $\cdot$ Temporal contiguity

Recall of one event often evokes memories of other events that occurred nearby in time. In the laboratory, this temporal contiguity effect is observed when subjects study and then recall lists of words: the order in which they recall the words tends to be similar to the original presentation order (for early reviews, see Postman 1971, 1972). Here we provide an overview of what we currently know about the contiguity effect by presenting 34 findings concerning how the effect is influenced by various factors and manipulations. Some of these come from a review of previous work, others are novel findings from the Penn Electrophysiology of Encoding and Retrieval Study (PEERS Healey \& Kahana, 2014; Lohnas \& Kahana, 2014; Miller, Kahana, \& Weidemann, 2012; see Appendix A for methods). Our overview is divided into

Electronic supplementary material The online version of this article (https://doi.org/10.3758/s13423-018-1537-3) contains supplementary material, which is available to authorized users.

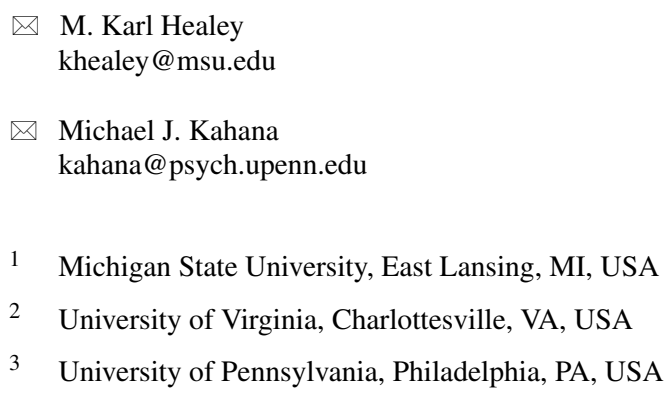

seven sections: basic properties of the contiguity effect in free recall, individual and group differences, manipulations of task parameters, manipulations of stimuli, manipulations of encoding tasks, contiguity in other memory tasks, and contiguity at long time scales. Table 1 lists the 34 findings we will discuss and their original references. We conclude with an evaluation of the ability of six different memory mechanisms to account for the findings: associative chaining, short-term memory, positional coding, chunking, contextual dynamics, and control processes.

\section{Basic properties of the contiguity effect in free recall}

\section{Finding 1: Temporal contiguity in free recall}

Kahana (1996) quantified the contiguity effect in immediate free recall by computing the probability of successively recalling items as a function of their distance from each other in the study list. After recalling an item studied in position $i$ of the list, one can measure the probability of transitioning to next recall an item studied in position $i+l a g$, conditional on the availability of that item for recall. This measure is called the lag conditional-response probability (lag-CRP). When the list is sufficiently long to allow for transitions at long lags, the lag-CRP decreases monotonically with $|\operatorname{lag}|$ (Fig. 1a plots the lag-CRP to $|l a g|=10$ for 24-item lists). For shorter lists, long-lag 
Table 1 References for benchmark contiguity effects

\begin{tabular}{|c|c|c|c|c|c|}
\hline Effect & Originally reported in & $\begin{array}{l}\text { Page in } \\
\text { current } \\
\text { paper }\end{array}$ & Effect & Originally reported in & $\begin{array}{l}\text { Page in } \\
\text { current } \\
\text { paper }\end{array}$ \\
\hline $\begin{array}{l}\text { 1. Temporal Conti- } \\
\text { guity in free recall }\end{array}$ & Kahana (1996) & 1 & $\begin{array}{l}\text { 28. Contiguity in } \\
\text { serial recall errors }\end{array}$ & Klein et al. (2005) & 9 \\
\hline 2. Forward asymmetry & Kahana (1996) & 3 & 29. Compound cuing in recog- & Schwartz et al. (2005) & 9 \\
\hline 3. Higher for early & Kahana (1996) & 3 & nition & & \\
\hline $\begin{array}{l}\text { and late output posi- } \\
\text { tions }\end{array}$ & & & $\begin{array}{l}\text { 30. Contiguity in paired } \\
\text { associates intrusions }\end{array}$ & Davis et al. (2008) & 10 \\
\hline $\begin{array}{l}\text { 4. Consistent across serial } \\
\text { positions }\end{array}$ & Current paper & 3 & $\begin{array}{l}\text { 31. Contiguity in prior list } \\
\text { institutions }\end{array}$ & Zaromb et al. (2006) & 10 \\
\hline $\begin{array}{l}\text { 5. Compound cuing } \\
\text { 6. Fluctuations in }\end{array}$ & $\begin{array}{l}\text { Lohnas and Kahana (2014) } \\
\text { Current paper }\end{array}$ & $\begin{array}{l}3 \\
4\end{array}$ & $\begin{array}{l}\text { 32. Across-list contiguity in } \\
\text { final free recall }\end{array}$ & $\begin{array}{l}\text { Howard et al. (2008) } \\
\text { and Unsworth (2008) }\end{array}$ & 10 \\
\hline $\begin{array}{l}\text { ing } \\
\text { 7. Consistency across } \\
\text { individuals }\end{array}$ & Healey and Kahana (2014) & 4 & 33. Contiguity outside the lab & $\begin{array}{l}\text { Moreton and Ward (2010) } \\
\text { and Uitvlugt and Healey } \\
\text { (in press) }\end{array}$ & 11 \\
\hline
\end{tabular}

8. Changes across

the lifespan

9. Personality and

clinical variables

10. Increases with

task experience

11. Positive corre-

lation with memory

ability

12. Positive correla-

tion with IQ

13. Larger for auditory

presentation

14. Independent of

recall modality

15. Larger for short lists

16. Robust to very fast presentation rates

17. Robust to very slow

presentation rates

18. Approximate time-

scale invariance

19. Reduced in orthographically distinct lists

20. Interacts with

emotional valance

21. Present when items

vary in assigned value

22. Robust to variation

in stimuli complexity

23. Dual-modality lists

24. Categorized lists

25. Temporal/semantic competition

26. Encoding task mani-

pulations

27. Mnemonic strategies

Incidental encoding $\begin{array}{lr}\text { Kahana et al. (2002) } & 4 \\ \text { Polyn et al. (2015) and } & 5 \\ \text { Pajkossy et al. (2017) } & \\ \text { Current paper } & 5 \\ \text { Sederberg et al. (2010) } & 5\end{array}$

Healey et al. (2014) 5

Current paper $\quad 5$

Current paper $\quad 6$

Current paper 6

Howard (2017) 6

Nguyen and McDaniel 6

(2015)

Howard and Kahana 6

(1999)

McDaniel et al. (2011) 6

Siddiqui and Unsworth $\quad 7$

(2011)

Stefanidi and Brewer 7

(2015)

Nguyen and McDaniel 7

(2015)

Cortis Mack et al. (2018) 7

Polyn et al. (2011) 7

Current paper 8

Long and Kahana (2017) 8

Bouffard et al. (2018) 8

Nairne et al. (2017) and 9

Healey (2018)
Table 1 (continued)

transitions tend to involve transitions to primacy or recency items, which can introduce a non-monotonicity in the lagCRP (Farrell \& Lewandowsky, 2008; Howard et al., 2009). Contiguity also manifests as faster inter-response times for absolute values of lag (Fig. 1b). ${ }^{1}$

\section{Finding 2: Forward asymmetry}

The contiguity effect is asymmetrical (Fig. 1a), such that forward transitions are more likely than backward transitions for small absolute values of lag (Kahana, 1996). The asymmetry effect has been shown in immediate free recall (where recall begins immedately after the last item is presented; Kahana, 1996), as well as in delayed (where a distraction filled interval introduces a delay between the last item and recall) and continual distractor free recall (where a distractor filled delay occurs after every item; Howard \& Kahana, 1999). As we will discuss below, some theories naturally predict this asymmetry, others do not.

\footnotetext{
${ }^{1}$ For a given lag, the conditional-response probability is computed by dividing the number of times a transition of that lag was actually made by the number of times it could have been made (Kahana, 1996). When determining the number of times a transition of a given lag could have been made, transitions that would lead outside the list boundaries are excluded (e.g., a +2 lag is impossible after recalling the 15 th item in a 16-item list), as are transitions to already-recalled items. The contiguity effect tends to be larger for the first few items recalled than for later output positions due to the strong recency effect, especially in immediate free recall (Farrell \& Lewandowsky, 2008; Howard et al., 2009). Therefore, in the remaining analyses we focus on $|\operatorname{lag}| \leq 5$, and unless we are specifically investigating the influence of output position, we exclude the first two outputs from the lag-CRP analyses in this paper.
} 


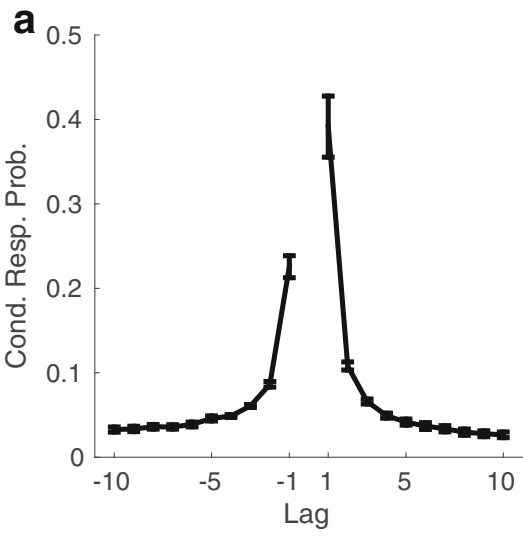

Fig. 1 The contiguity effect: Recall of one event triggers recall of other events that occurred near in time. a The conditional-response probability as a function of lag (lag-CRP) shows the probability of recalling an item from serial position $i+l a g$ immediately following recall of an item from serial position $i$. b The conditional response latency as a function of lag (lag-CRL) shows the mean inter-response time

\section{Finding 3: Higher for early and late output positions}

One of the first factors shown to influence the size of the contiguity effect was position in the output sequence (Kahana, 1996). As shown in Fig. 2a, in delayed free recall the contiguity effect is large for the first pair of items output and then drops, but remains robust, for intermediate output positions before rebounding for later outputs (for discussions of the sources of this effect see Farrell \& Lewandowsky, 2008; Howard et al., 2009; Kahana, 1996).

\section{Finding 4: Consistent across serial positions}

We can also examine contiguity as a function of serial position at study. Figure $2 b$ shows lag-CRPs in delayed free recall for transitions between items $i$ and $j$ separately for cases where item $i$ was from early, mid, and late serial positions. A clear contiguity effect is present across input positions. For early serial positions, the negative-lag conditional response probabilities are elevated, consistent with Murdock's (1974) observation that after recalling several items from late serial positions, subjects tend to jump back to early serial positions.

\section{Finding 5: Compound cuing in free recall}

Reanalyzing data from several previous studies (including both immediate and delayed free recall), Lohnas and Kahana (2014) found that the contiguity effect was larger when the previous transition had been to an adjacent item (lag $=$ $+1)$ than when it had been to a remote item $(|\operatorname{lag}|>3)$, suggesting that the retrieval cue for a given item includes information from multiple prior recalls-a compound cue.

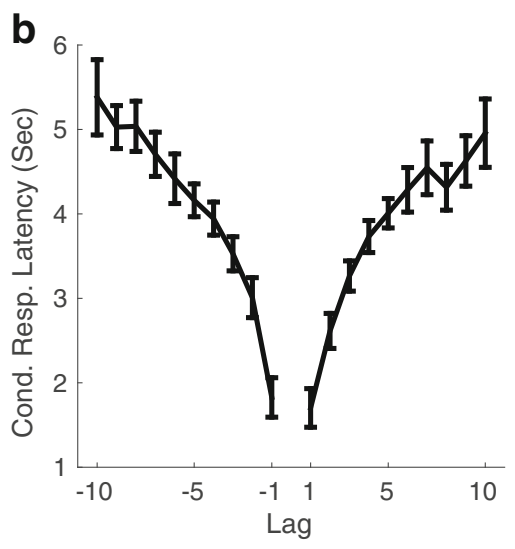

between successive recalls of items from serial positions $i$ and $i+l a g$. Data are from Experiment 4 of the Penn Electrophysiology of Encoding and Retrieval Study (PEERS). Subjects studied lists of 24 words for delayed free recall. Error bars are $95 \%$ within-subject confidence intervals (Loftus \& Masson, 1994)

\section{Finding 6: Contiguity is not due to fluctuations in efficiency of encoding}

The efficiency of encoding varies from moment to moment (Sadeh et al., 2015; Kahana et al., 2005b; Hintzman \& Hartry, 1990). This variation could, in principle, produce an artificial contiguity effect (for a related point, see Hintzman, 2016). To see how, imagine a subject whose encoding efficiency starts high and fades over the course of a list. Consider what would happen if every time they studied a list, they always successfully encoded the first two items but later items were each encoded only $10 \%$ of the time. In other words, imagine a subject with a very pronounced primacy effect. Assume this subject always begins recall by outputting the item from serial position 1. From there, it would always be possible to transition to serial position 2 . But only $10 \%$ of the time would it be possible to transition to serial position 3 , or 4 , or any later position. That is, making a lag of +1 would always be a possibility, but any given lag $>1$ would be possible only $10 \%$ of the time. Thus, even if this subject completely ignored lag when making transitions and instead randomly selected a successfully encoded item, they would still show a bias toward lag +1 transitions-an artificial contiguity effect. This artificial effect is not limited to our example of extreme primacy. It will arise whenever fluctuations in efficiency of encoding are autocorrelated across serial positions.

To further illustrate, we created simulated data in which the contiguity effect is an artifact of fluctuations in efficiency of encoding. We started with an idealized serial position curve that has two "pockets" of well-encoded items separated by many poorly encoded items (see the inset in Fig. 3a), simulating autocorrelated changes in encoding 


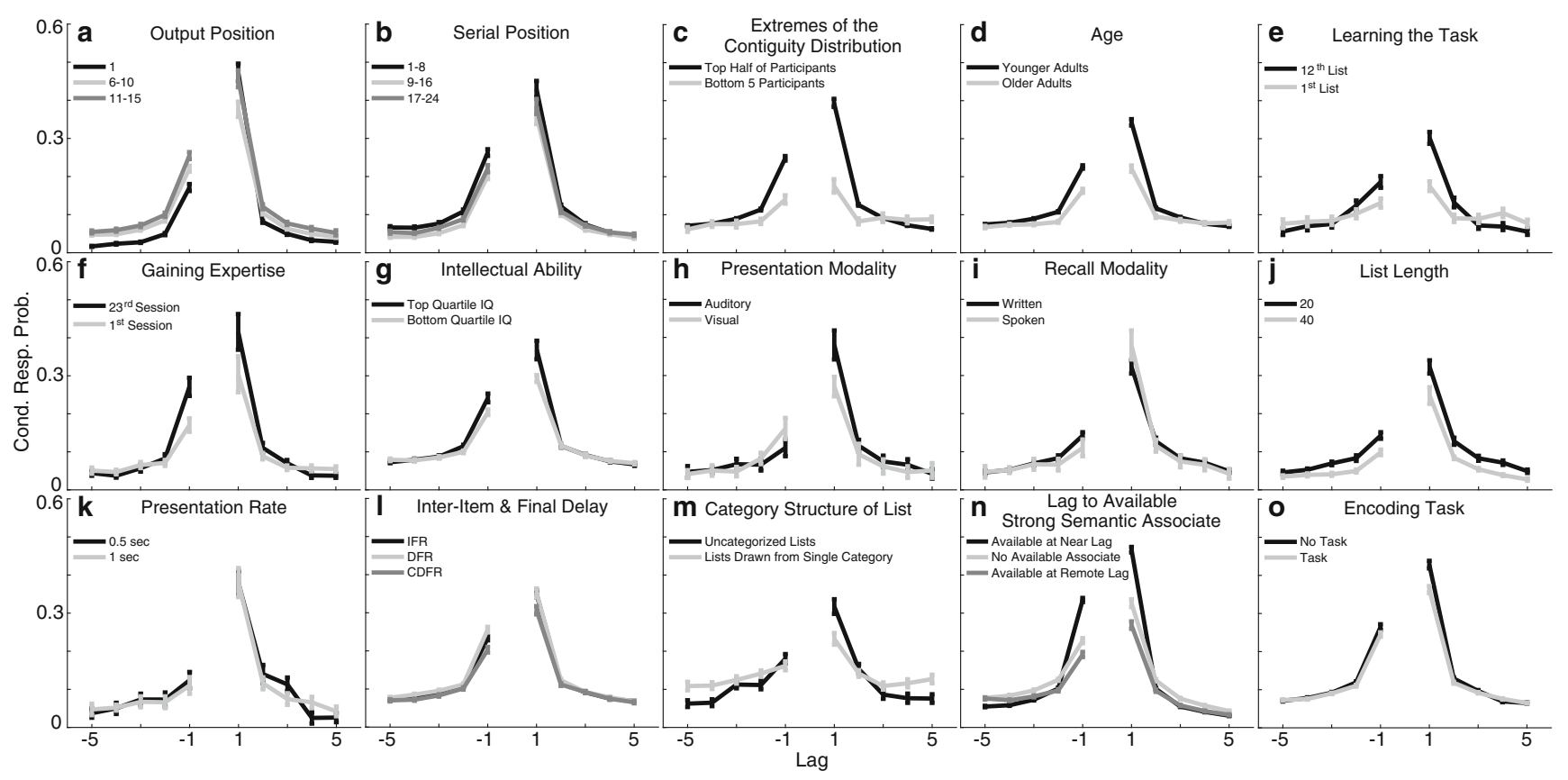

Fig. 2 Many variables influence the contiguity effect. a Output position 1 vs. output positions 6-10 vs. 11-15 from PEERS Experiment 4. b Transitions originating from serial positions 1-8, 9-16, and 1724 from PEERS Experiment 4. c Subjects with temporal factor scores in the top half of the distribution vs. subjects with the 5 lowest scores across both age groups in PEERS Experiment 1. d Younger vs. older adults in PEERS Experiment 1. e First vs. last (12th) list in the screening session of PEERS. f Naïve subjects' first vs. 23rd session in PEERS Experiment 4. g Top vs. bottom quartile of the younger adult IQ distribution in PEERS Experiment 1 . h Auditory vs. visual presentation in the $1 \mathrm{sec}$ presentation rate condition in Experiment 1 of Murdock and Walker (1969). i Written vs. spoken recall in Murdock

efficiency. We then used this curve to define a binomial distribution of recall success for each serial position. Then, for each of 100,000 simulated lists, we predetermined which serial positions would be successfully recalled by randomly and Walker (1969) and Murdock (1962) respectively (20-item lists presented auditorily for $1 \mathrm{sec} /$ item in both cases). $\mathbf{j}$ List length $20 \mathrm{vs.} 40$ in Murdock (1962, $1 \mathrm{sec}$ presentation rate). k Presentation rates of $0.5 \mathrm{sec}$ vs. $1 \mathrm{sec}$ in Experiment 1 of Murdock and Walker (1969). 1 Immediate, delayed, and continual distractor recall conditions from PEERS Experiments 1-3. m Uncategorized lists vs. lists drawn from a single category in McCluey et al. (2018). $\mathbf{n}$ Transitions originating from items that had a strong associate (WAS $\cos (\theta)>.7)$ available only at lags $>5$ vs. items that had a strong associate available at lags $\leq 2$ vs. items that had no strong associates available in PEERS Experiments 1-3. o Lists with vs. without an encoding task in immediate free recall lists of PEERS Experiments 1-3

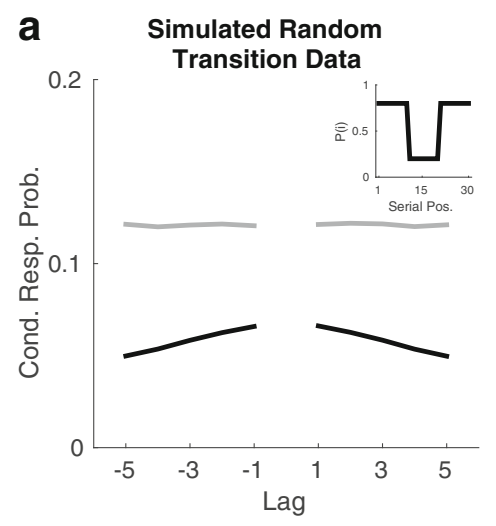

Fig. 3 Conditionalizing on availability of both items $i$ and $j$ does not eliminate the contiguity effect. a A simulated artifactual contiguity effect from a model in which the probability of successful encoding varies by serial positions (see inset) but transitions between items drawing from the distribution of each serial position. The model then output these recalled words in random order (i.e., input order does not directly influence output order). The black line in Fig. 3a shows that these simulated data do
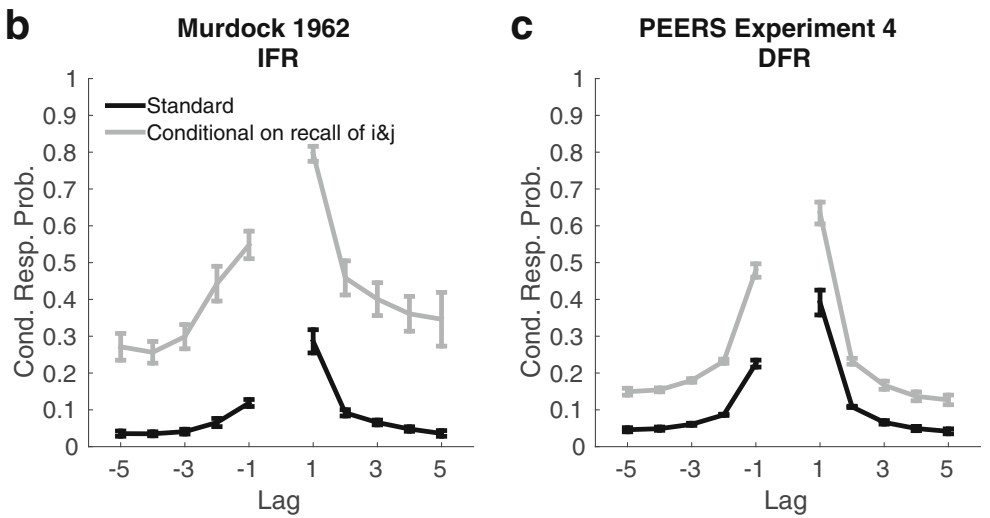

are random with respect to study lag (see Appendix B for details). b Immediate recall of 30-item lists from Murdock (1962). c Delayed free recall of lists of 24 items in PEERS Experiment 4. Error bars are 95\% within-subject confidence intervals (Loftus \& Masson, 1994) 
indeed exhibit an artifactual contiguity effect when the lagCRP is computed in the standard way (though the effect is smaller and more linear than in real data).

It is possible, however, to eliminate the influence of fluctuations in encoding success by recomputing the lagCRP conditional on recall of both item $i$ and item $j$. That is, we can equate rate of successful encoding across lags by considering a transition of a given lag possible only if both items involved in that candidate transition were actually successfully recalled at some point in the recall sequence. The gray line in Fig. 3a shows that this adjustment completely eliminates the artifactual contiguity effectwhen considering only items that are successfully recalled, the lag-CRP from the simulated data is flat. Is the contiguity effect in real data an artifact? Panels b and c of Fig. 3 show that it is not-even when the lag-CRP is conditionalized on recall of both item $i$ and item $j$, a strong contiguity effect remains. In the Supplemental Materials, we apply this adjustment to all of the lag-CRPs presented in the main text - in no case does it eliminate the contiguity effect. That is, variation in encoding cannot account for the contiguity effect.

\section{Individual and group differences}

Most work on the contiguity effect has reported data averaged across individuals. But recent work considering individual differences and differences between subgroups has revealed several important findings.

\section{Finding 7: Consistency across individuals}

Healey and Kahana (2014) tested 126 young adults in the immediate free recall task and found that, depending on how contiguity was measured, $96 \%-100 \%$ of individuals showed a contiguity effect. To illustrate this across-subject consistency here, we computed temporal factor scores (Polyn et al., 2009) for each younger and older adult in Experiment 1 of PEERS. The temporal factor score for a given transition is the percentile rank of the actual lag of the transition with respect to the lags of all transitions that were possible at that time, averaging these percentiles across all of a subject's transitions gives their overall factor score. Computing this score for each subject provides an acrosssubject distribution of the size of the temporal contiguity effect. Figure 2c shows the average lag-CRP for subjects in the top half of the distribution and compares it with the lag-CRP of the 5 subjects with the lowest temporal factor scores. Even the subjects with the lowest temporal factor scores show a clear contiguity effect.

\section{Finding 8: Changes across the lifespan}

The magnitude of the contiguity effect varies across the lifespan, increasing in childhood (Lehman \& Hasselhorn, 2010, 2012; but see Jarrold et al., 2015) and decreasing in old age (Kahana et al., 2002; Healey \& Kahana, 2016; Wahlheim \& Huff, 2015; Wahlheim et al., 2017)—-though even those with the lowest levels of contiguity still show a clear effect. Figure 2d shows lag-CRPs for younger (18-30 years) and older adults (61-85 years) in PEERS Experiment 1 (immediate free recall).

\section{Finding 9: Personality and clinical variables}

Several studies have found that personality variables and clinical conditions correlate with changes in temporal contiguity in delayed free recall. Polyn et al. (2015) found that schizophrenic patients exhibited reduced temporal contiguity relative to a control group. Sahakyan and Kwapil (2018) found a reduction in contiguity relative to control among patients with negative schizotypy but not among those with positive schizotypy. Murty et al. (2018) found a similar reduction in contiguity among a group of patients suffering their first episode of psychosis. Pajkossy et al. (2017) found that a bias for short lag transitions was positively correlated with trait worry but negatively correlated with trait anxiety. Finally, Gibson et al. (in press) have found that temporal contiguity is increased in individuals with ADHD relative to controls even though overall recall is decreased. These early studies suggest that temporal contiguity may provide a more sensitive measure than traditional neuropsychological tests that focus mainly on recall accuracy.

\section{Finding 10: Increases with task experience}

In addition to changing across the lifespan, the magnitude of the contiguity effect changes as a subject gains experience with the free recall task. To examine contiguity at the naïve end of the practice spectrum, we looked at data from the initial screening session of PEERS in which subjects studied 12 lists of 16 items for immediate free recall. Figure 2e shows the lag-CRP for subjects' 1 st free recall list versus their 12th list. A clear contiguity effect is seen on the 1st list, but it grows larger by the 12th list (see also, Healey, 2018).

To examine how contiguity evolves as subjects gain expertise in the task, we consider data from PEERS Experiment 4. In this experiment, a group of subjects who were initially naïve to the free recall task completed 24 sessions of delayed free recall after the initial screening session. In each session, subjects studied 24 lists of 24 items for delayed recall (cf. Experiment 1 which used immediate 
recall; as we discuss below, test delay has only a small effect on contiguity). Figure $2 \mathrm{f}$ shows that a large contiguity effect is present in the 1st session but grows even larger by the 24th.

\section{Finding 11: Positive correlation with memory ability}

The fact that a qualitatively similar contiguity effect is consistently observed across individuals and age groups should not be taken to mean that quantitative variation in the magnitude of the effect is unimportant. Indeed, subjects who show the most contiguity also recall the most words (Healey et al., 2014; Sederberg et al., 2010; Spillers \& Unsworth, 2011). Figure $4 \mathrm{a}$ shows the correlation between contiguity (measured by temporal factor scores) and overall immediate recall accuracy in PEERS Experiments 1-3.

\section{Finding 12: Positive correlation with IQ}

Contiguity in standard immediate free recall also correlates with intellectual ability (Healey et al., 2014) as measured by WAIS IQ. The correlation between temporal contiguity and IQ remains even after accounting for variance in other aspects of recall dynamics, such as semantic contiguity (Healey et al., 2014). Figure $4 \mathrm{~b}$ shows the correlation between contiguity and IQ among the younger adults in PEERS Experiments 1-3. Figure $2 g$ illustrates how the size of the contiguity effect increases with IQ by showing the lag-CRPs for the younger adults in the top and bottom quartile of the younger adult IQ distribution.

\section{Manipulation of task parameters}

We have seen that contiguity is modulated (though not eliminated) by various inter- and intra-individual differences.

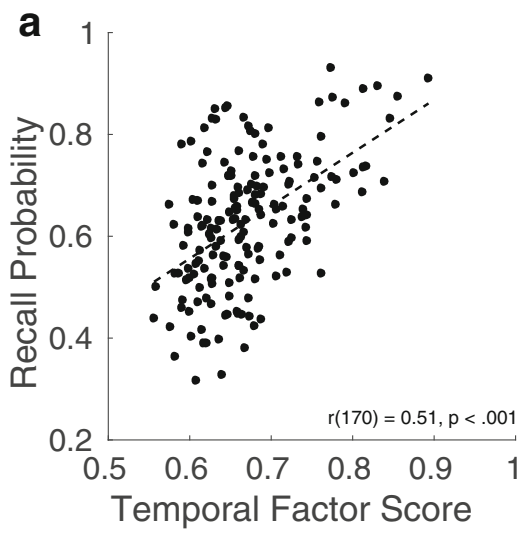

Fig. 4 Individual differences in contiguity predict memory performance and IQ. a The correlation between temporal factor scores and overall recall probability. Temporal factor scores give the average percentile ranking of the temporal lag of each actual transition with respect to the lags of all transitions that were possible at that time. b
Is it also modulated by differences in how the free recall task is administered? Here, we will examine the influence of a variety of task parameters.

\section{Finding 13: Larger for auditory presentation}

Auditory presentation is known to increase overall recall, particularly for recency items (Murdock \& Walker, 1969). Figure $2 \mathrm{~h}$ shows that auditory presentation also increases the contiguity effect in immediate free recall.

\section{Finding 14: Independent of recall modality}

Some studies have subjects write down their recalls, others have subjects say them aloud. Does modality of recall influence the contiguity effect? It might because writing the words down as you recall them (as opposed to saying them aloud) allows you to see the words you have already recalled and more easily use them as cues to recall their listneighbors. Yet, as shown in Fig. 2i comparing data from Murdock and Walker (1969) and Murdock (1962) (both immediate recall), the effect of spoken versus written recall is small, suggesting that contiguity does not depend on having previous recalls visually available for use as cues.

\section{Finding 15: Larger for short lists}

List length is another influential variable in recall experiments (Murdock, 1962). Cortis Mack et al. (2015) examined lag-CRPs in immediate free recall at ten different list lengths between 2 and 15, and found a contiguity effect at all lengths. Figure $2 \mathrm{j}$ compares lists of 20 versus 40 items in the Murdock (1962) dataset. Although both lengths show a clear contiguity effect, the effect is larger for the shorter lists.

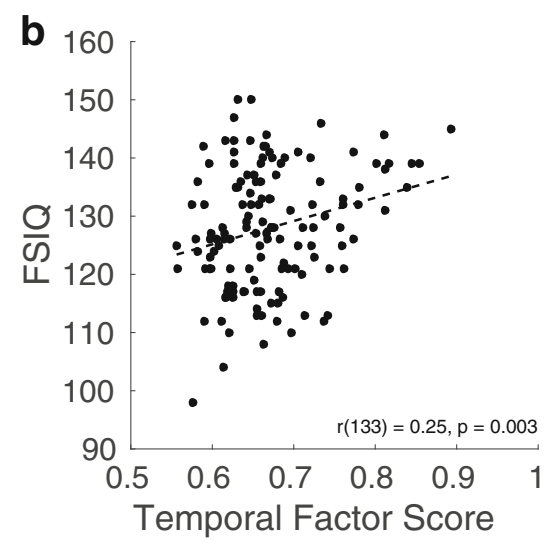

The correlation between temporal factor scores and full-scale Wechsler Adult Intelligence Scale IV IQ (FSIQ). Computed using all immediate free recall trials from younger adults in Experiments 1-3 of the Penn Electrophysiology of Encoding and Retrieval Study (PEERS) 


\section{Finding 16: Robust to very fast presentation rates}

Presentation rate might strongly influence how items are encoded simply because longer presentation rates presumably give subjects more time to engage whatever processes produce contiguity. Figure $2 \mathrm{k}$ shows a robust contiguity effect in immediate free recall for presentation rates of 0.5 seconds and 1 second. Howard (2017) examined very fast presentation rates and found a robust contiguity effect at rates as fast as 4 words per second. At 8 words per second, they found the lag-CRP began to flatten, perhaps due to an attentional blink-like effect.

\section{Finding 17: Robust to very slow presentation rates}

At the other extreme, Nguyen and McDaniel (2015, Experiment 3) examined lag-CRPs in delayed free recall when subjects were allowed to self pace their study of line drawings of familiar objects. Subjects studied each picture for an average of over 6 seconds but still showed a robust contiguity effect. Overall, then, the contiguity effect seems relatively insensitive to presentation rate.

\section{Finding 18: Approximate time-scale invariance}

In immediate free recall, items are presented with a short inter-item delay and subjects are asked to recall the words immediately after the presentation of the final list item. Delayed free recall adds a retention interval by asking subjects to engage in a distractor task for a period of time after the final item but before recall. Continual distractor free recall (CDFR) also has a delay after the final item but also introduces a distractor-filled delay between each item during presentation (Bjork \& Whitten, 1974). Figure 21 shows that all three versions of the task produce a clear contiguity effect (Howard \& Kahana, 1999; Bhatarah et al., 2006), with a slightly lower CRP at lag $=+1$ for CDFR (cf. Howard, 2004). That is, contiguity is relatively invariant to changes in time scale (see below for discussion of timescales on the order of days and years)

\section{Manipulation of stimuli}

We have seen that the details of how stimuli are presented (modality, rate, etc.) can modulate the size of the contiguity effect (though, like individual differences, not eliminate it). But most of these studies have randomly drawn stimuli from pools of common words. How does varying the nature of the stimuli impact contiguity?

\section{Finding 19: Reduced in orthographically distinct lists}

Ward et al. (2003) examined the effects of word frequency on immediate free recall. They found a strong contiguity effect for both high and low frequency words in both mixed and pure lists. Similarly, in a delayed free recall task, McDaniel et al. (2011) had subjects study lists that included orthographically distinctive items (i.e., words with unusual letter combinations such as lynx, methyl, knoll, calypso) and orthographically common items. The lists were either pure (all either distinctive or common) or mixed. They found substantial contiguity effects in mixed lists and pure common lists but found no contiguity effect in pure distinct lists. These results suggest that orthographically distinct words may disrupt the mechanisms that generally produce contiguity. Indeed, this is the only study we are aware of that fails to find contiguity in the free recall of deliberately encoded items. Bean et al. (2017) recently replicated the relevant conditions from McDaniel et al. (2011) with a sample of 338 subjects (cf. 36 in McDaniel et al., 2011). They replicated the finding that orthographic distinctiveness substantially reduces the contiguity effect. Their larger sample size, however, revealed a significant effect even for pure distinctive lists. That is, orthographic distinctiveness reduces, but does not eliminate, the contiguity effect.

\section{Finding 20: Interacts with emotional valance}

Another aspect of meaning that influences recall order is the emotional content of stimuli (Long et al., 2015; Siddiqui \& Unsworth, 2011). Siddiqui and Unsworth (2011, Experiment 1) gave subjects delayed free recall lists that were composed of eight positively valanced words, eight negatively valanced words, and eight neutral words, presented in random order. Subjects showed a modest temporal clustering effect, even though the emotional context provided the opportunity to cluster recalls based on valence. In a second experiment, the researchers made the emotional content of the items more salient by asking subjects to rate the pleasantness of each item during study. This manipulation further reduced the level of temporal contiguity, without eliminating it entirely.

\section{Finding 21: Present when items vary in assigned value}

There is considerable evidence that the perceived importance of information influences memory performance (e.g., Castel, 2005; May, Rahhal, Berry, \& Leighton, 2005). Even assigning arbitrary value to items can influence how information is remembered (Castel et al., 2002). Stefanidi 
et al. (2018) examined the influence of such value assignments on contiguity. In 10-item delayed free recall lists, they assigned each item a value between 1 and 10 and told subjects that the items with the highest values were the most important to remember. In one condition, values were randomly assigned to serial positions, in another condition, values were assigned to serial position in ascending order (i.e., the value of serial position $1=1$, value of serial position $2=2$, etc.), and in another, they assigned values in decreasing order of serial positions (i.e., the value of serial position $1=10$, value of serial position $2=9$, etc.). One could reasonably expect that these conditions would strongly influence both the encoding and search strategies subjects engage in (e.g., trying to recall the highest value items first). Indeed, recall probability increased as a function of value in all conditions. Yet, they found a typical forward asymmetric lag-CRP in all conditions, and the degree of contiguity did not differ substantially from a control condition in which subjects were told to ignore the numbers presented along with each item rather than being told they represented the value of the items. They did find however, that presenting items in order of value (either ascending or descending) substantially increased the temporal contiguity effect-assigned value and temporal proximity had additive effects.

\section{Finding 22: Robust to variation in stimuli complexity}

Most of the studies we have reviewed used words as stimuli. In terms of perceptual complexity, words are quite impoverished compared to the things we usually want to remember outside the laboratory (e.g., complex visual scenes). Although contiguity was not their main focus, Nguyen and McDaniel (2015) suggested that memory for pictures might show a reduced contiguity effect due to less reliance on contextual details. Their stimuli were line drawings that were either complex (e.g., a drawing of a car including details like door handles and headlights) or simple (e.g., an outline of a car with no details). Stimuli were assigned to either pure lists of complex pictures, pure lists of simple pictures, or mixed lists. They found a clear contiguity effect with a forward asymmetry in all conditions with no significant differences between list conditions. Perhaps, because the pictures are nameable, subjects translated them into verbal codes. Cortis Mack et al. (2015) examined contiguity under a variety of conditions designed to reduce reliance on verbal codes (e.g., remembering locations of tactile stimulation of the face). They too found clear contiguity effects with all stimulus types. As we will see below, temporal contiguity has also been demonstrated in recall of complex memories formed outside the lab such as autobiographical events (Moreton \& Ward, 2010) and news stories (Uitvlugt \& Healey, in press).

\section{Finding 23: Dual-modality lists}

In the previous section, type of stimuli varied from list to list. Cortis Mack et al. (2018) varied it within a single immediate free recall list. At each serial position of the list, a word was presented over headphones and a spatial location was simultaneously presented as a dot on a computer screen. Subjects were then asked to freely recall both the words (by saying them aloud) and dots (by clicking on the screen) in any order they wanted. Recall transitions could be either within-modality (e.g., recalling two words in succession) or between modality (e.g., recalling a word then recalling a dot). Because words and dots were presented simultaneously, lag $=0$ transitions were possible (e.g., recalling a dot and next recalling the word that was presented at the same time). These $l a g=0$ transitions were the most frequent type-even when subjects could cluster by stimulus type, temporal proximity guided memory search. In two additional experiments, they pretested lists that alternated between words and dots (rather than presenting two stimuli simultaneously) and again found a strong preference for temporally proximate transitions at the expense of withinmodality transitions.

\section{Finding 24: Categorized lists}

The presence of strong semantic associations among list items could mitigate the need to rely on temporal associations to guide recalls. Yet, the contiguity effect is seen even when every item is drawn for the same semantic category (Miller et al., 2013), which should provide very strong semantic cues. McCluey et al. (2018) directly assessed the influence of such strong cues by having subjects study lists in which each item was drawn from the same category or each item was drawn from a different category. As shown in Fig. $2 \mathrm{~m}$, although contiguity was modestly reduced in the same-category lists, it was still substantial and robust (see also Kintsch, 1970). Polyn et al. (2011) found that when immediate free recall lists were composed of 8 items drawn from each of three categories presented in a random order, contiguity actually emerged at two different levels: when subjects transitioned between items from the same category they preferred category members that were presented nearby in time and when they transitioned from one category to another, they preferred categories that were presented nearby in time. That is, even when subjects have strong semantic associations to rely on, temporal associations still powerfully influence recall order.

\section{Finding 25: Temporal/semantic competition}

Even when a list does not contain a clear category structure, more subtle semantics among items matter (Bousfield et al., 
1954; Howard \& Kahana, 2002b). Sometimes temporal and semantic associations will tend to guide memory search in the same direction, as when a close semantic associate of the just-recalled word was studied in an adjacent serial position. Other times, the two types of associations can compete, as when a strong semantic associate of the just-recalled item was studied in a remote serial position. The PEERS dataset allows us to assess contiguity in these two situations (for a similar analysis focusing on semantic contiguity see Howard \& Kahana, 2002b). Each list in PEERS was constructed such that it had two pairs of high-similarity words with the members of one pair being presented in adjacent serial positions and the members of the other pair being separated by at least two other items (see Appendix A for details on list design). We examined recall transitions from items in cases in which a high-similarity associate of the item was available at a near lag $(\leq 2)$. In this case, temporal and semantic information complement each other. We also examined transitions from items in cases in which a high-similarity associate of the item was available only at a remote lag ( $>5$ ). Here, temporal and semantic information compete with each other. As a control, we examined transitions from items in cases in which no strong associate of the item was available at any lag. As seen in Fig. 2n, the presence of a strong associate modulated the lag-CRP in a systematic way, making it steeper when the associate was available at a near lag and making it shallower when the associate was available at a distant lag.

\section{Encoding manipulations}

So far we have considered cases in which subjects are told to study items for a memory test, but are given no specific instructions on how to study them. How is contiguity influenced by the nature of the processing subjects engage in during encoding?

\section{Finding 26: Encoding task manipulations}

In PEERS, subjects were asked to carry out a processing task for all items in some lists (a size or an animacy judgment) whereas on other lists, they were given no specific encoding task. As seen in Fig. 2o, although a clear contiguity effect emerges in both conditions, it is modestly smaller when subjects are given a specific task (Long \& Kahana, 2017). One limitation of this finding is that because encoding task was manipulated within-subject, subjects could have adopted a contiguity-generating strategy across all lists, regardless of assigned processing task-the reduction of contiguity might be even larger in a betweensubjects design. Overall, the data suggest that imposing an arbitrary encoding task disrupts the processes that generate contiguity.

\section{Finding 27: Mnemonic strategies}

Do all processing tasks reduce contiguity, even those that are not arbitrary but are instead intended to improve memory? Bouffard et al. (2018) used delayed free recall to test the effect of such mnemonic strategies by comparing lagCRPs when subjects were given no encoding strategy with lag-CRPs when subjects were given either the method of loci, a similar method that involved associating items to points on an autobiographical time-line rather than spatial locations, or a method involving linking items to steps of a well-known sequence (e.g., making a sandwich). All of these methods increased at least one measure of temporal contiguity: The method of loci increased contiguity in both the initial delayed recall and a final free recall test (i.e., recall items from any list presented in the experiment), whereas the autobiographic and sequence method increased contiguity only in final free recall.

\section{Finding 28: Incidental encoding}

Almost all of the tasks we have considered thus far explicitly asked subjects to memorize a list of stimuli and therefore encourage processing that facilitates encoding. Does temporal contiguity emerge when encoding is incidental and there is no incentive to attend to, let alone encode, the temporal distance between events? Data from a variety of studies in which incidental encoding is followed by order reconstruction tasks suggest that subjects do encode information about temporal contiguity even when they are not deliberately studying (Glenberg and Bradley 1979; Nairne 1991; Nairne, Cogdill, and Lehman 2017; for a review see Healey 2018). But the fact that people have access to temporal information does not necessarily mean they will use it to guide a free memory search after incidental encoding. We are aware of only two studies that have directly tested for temporal contiguity after incidental encoding using modern measures (Burns, 1996, did report a measure of the number of $|\operatorname{lag}|=1$ transitions, but did not test if they were more frequent than other lags).

Nairne et al. (2017) reported a series of experiments investigating the survival processing effect (Nairne et al., 2007; Nairne \& Pandeirada, in press). In the first experiment, subjects completed a survival processing task that made no mention of memorizing the items: they viewed a list of items and for each rated its relevance to a survival (or control) scenario. But there was a surprise delayed free recall test approximately two minutes after the end of the list. Temporal clustering was not significantly above chance 
as assessed by the temporal factor score even though subjects recalled a substantial number of items (approximately $45 \%$ accuracy across conditions). A second experiment used a different processing task as a control to the survival processing task. Again, there was no evidence of temporal contiguity_even though recall levels were high.

Healey (2018) followed up on these findings by presenting over 2000 subjects with a surprise delayed free recall test after various incidental encoding tasks. The results show that incidental encoding substantially reduces the temporal contiguity effect. But it does not eliminate it: The average effect size across the different incidental encoding tasks was small (Cohen's $d$ was approximately 0.13 ) but reliably greater than zero.

Taken together, the evidence from incidental encoding studies suggests that the temporal contiguity effect occurs automatically, but is powerfully amplified by the intent to encode. The finding that incidental encoding dramatically reduces contiguity without substantially reducing recall levels is problematic for models that posit a tight coupling between recall and contiguity (for a discussion see Healey, 2018).

The studies reviewed in this section highlight the importance of how items are processed at encoding. Some types of processing result in less temporal information being encoded. Although much more work needs to be done, the current evidence suggests that manipulations that encourage item-specific processing over relational processing tend to produce smaller contiguity effects (McDaniel et al., 2011; Nguyen \& McDaniel, 2015; Bouffard et al., 2018).

\section{Contiguity in other tasks}

\section{Finding 29: Contiguity in serial recall errors}

As has been repeatedly demonstrated, serial recall relies on many of the same mechanisms as free recall (Bhatarah et al., 2006; Ward et al., 2010; Spurgeon et al., 2015; Spurgeon et al., 2014). Thus, there may be similar contiguity effects in the two tasks. Indeed, both some early data (Lee \& Estes, 1977) and recent analyses using lag-CRP methodology show that although there is a strong forward bias, serial recall exhibits a contiguity effect (Spurgeon et al., 2015; Solway et al., 2012) that extends over multiple lags in both the forward and backward directions (Klein et al., 2005). Errors in serial recall are even more informative than contiguity among correct recalls. Applying lag-CRP analyses to recalls following an order error shows a contiguity effect with a clear gradient across lags (Kahana \& Caplan, 2002; Solway et al., 2012). Although details of the task such as list length and whether subjects are allowed to skip items appear to impact the exact pattern of errors observed (Osth \& Dennis, 2015; Farrell et al., 2013), current evidence suggests that serial recall errors are temporally graded (for related evidence from order reconstruction tasks, see Nairne, 1991).

\section{Finding 30: Compound cuing in recognition}

In Schwartz et al. (2005), subjects studied lists of pictures for a recognition test. During test, items that had been studied in adjacent positions in the study list were sometimes probed successively during the test. If temporal associations had formed between items during study, having two successive probes be from adjacent list positions should help recognition because the first item will help cue the second. Such a benefit was observed. Moreover, upon making a high-confidence response for probe $i$, subjects' probability of making a high-confidence response to probe $i+1$ was a decreasing function of the $|l a g|$ between $i$ and $i+1$ in the study list. That is, if you were highly confident about one probe, then you would be highly confident about the next probe if it came from a nearby position in the list. This was true even after accounting for autocorrelation in quality of encoding.

Sadeh et al. (2015) reported a similar result in free recall using the remember/know paradigm. They found that transitions from items for which the subject "remembered" the item was on the list showed a stronger contiguity effect than transitions from items which they simply "knew" were on the study list.

Averell et al. (2016) replicated the basic Schwartz et al. (2005) finding that matching test order to study order facilitates recognition. Critically, whereas Schwartz et al. (2005) drew their stimuli from a relatively small pool of pictures, Averell et al. (2016) used word lists generated from a large pool of words. The use of a large pool rules out the possibility that temporal proximity is confounded with chance semantic similarities among adjacent list items (Hintzman, 2016).

\section{Finding 31: Contiguity in paired associates intrusions}

In paired associate learning, subjects have a strong incentive to form associations between items in the same pair but have absolutely no reason to form associations between items in temporally adjacent pairs. In fact, forming such acrosspair associations should actually be harmful as it creates a powerful source of interference (Primoff, 1938). Despite these strong incentives to avoid inter-pair associations, analyses of errors in cued recall suggest subjects do indeed form inter-pair associations. Davis et al. (2008) examined cases in which subjects incorrectly recalled (intruded) an item from an uncued pair. As in a lag-CRP analysis, they conditionalized the probability of intruding an item from a 
given lag on the availability of the pair at that lag. These intrusions showed a clear, forward-biased, contiguity effect that extended across many lags (for a similar finding, see Caplan, Glaholt, \& McIntosh, 2006).

\section{Long-range contiguity}

In most list learning tasks, items are separated by a few seconds. Outside the laboratory, events can be separated by minutes, hours, or more. Here we review several cases where contiguity emerges at these longer time scales.

\section{Finding 32: Contiguity in prior list institutions}

When we examine prior-list intrusions (PLI; erroneously recalling a word that was not on the current list but was on a prior list), we see they are most likely to come from the most recent list (Murdock, 1974), suggesting temporal proximity influences an item's accessibility. Zaromb et al. (2006) directly investigated the influence of temporal associations on the commission of PLIs by creating lists that contained some items that were repeated from earlier lists. Subjects were clearly instructed to recall items from the current list only. They found that PLIs were more likely to follow successful recall of one of the repeated items than recall of a non-repeated item. Moreover, these repetition-evoked PLIs tended to be from the same list as the just-recalled repeated item and from serial positions near to the repeated item's position in the original list. Even clearer evidence of the role of temporal associations in driving intrusions can be seen by examining cases in which subjects make several PLIs in succession: such chains of intrusions showed a clear contiguity effect such that subjects were most likely to transition between PLIs that were temporally contiguous in the original list.

\section{Finding 33: Across-list contiguity in final free recall}

Across-list temporal associations can also be examined in studies that include a final free recall phase after multiple lists have been studied and recalled. Not surprisingly, final free recall transitions between words studied in the same list show a clear contiguity effect (Howard et al., 2008; Unsworth, 2008; Loaiza \& McCabe, 2012). But contiguity manifests even when subjects do not transition between items from the same list: when they make an across-list transition it tends to be to items presented in temporally adjacent lists (Howard et al., 2008; Unsworth, 2008). Across-list contiguity is also apparent in the list-lag of errors when subjects are probed with an item from one list and asked to recall another item from the same list but erroneously recall an item from a different list (Kılıç et al., 2013). These across-list contiguity effects suggest that subjects are encoding information about temporal distance at the level of lists, even when it is a potential source of interference.

Figure 5 replicates the final free recall across-list contiguity effect with data from PEERS. This across-list CRP considers only transitions during final free recall that consist of correct recalls from one list to correct recalls of a different list. This analysis controls for the fact that it becomes less likely to transition to a particular list as the number of items that have already been correctly recalled from that list increases. For example, if a subject recalls an item from list \#4, it is possible that the next item they recall correctly could be anything that has not already been recalled. If the subject had previously recalled 5 words from list $\# 2$, and 10 words from list $\# 9$, then there are 11 different items from list \#2, and 6 different items from list \#9 (assuming 16 item lists) that could be transitioned to. We would increment the denominator for the -2 and +4 possible lags accordingly. The numerator is incremented in the same way; if the next correct recall turns out to be from list \#6, and three words had already been recalled from that list, then the +2 lag will be incremented by 13. Following Howard et al. (2008), we also created a surrogate dataset to control for the effects of recency and autocorrelated goodness of encoding. To construct this surrogate data, we took each pair of acrosslist transitions that were made and then shuffled them so

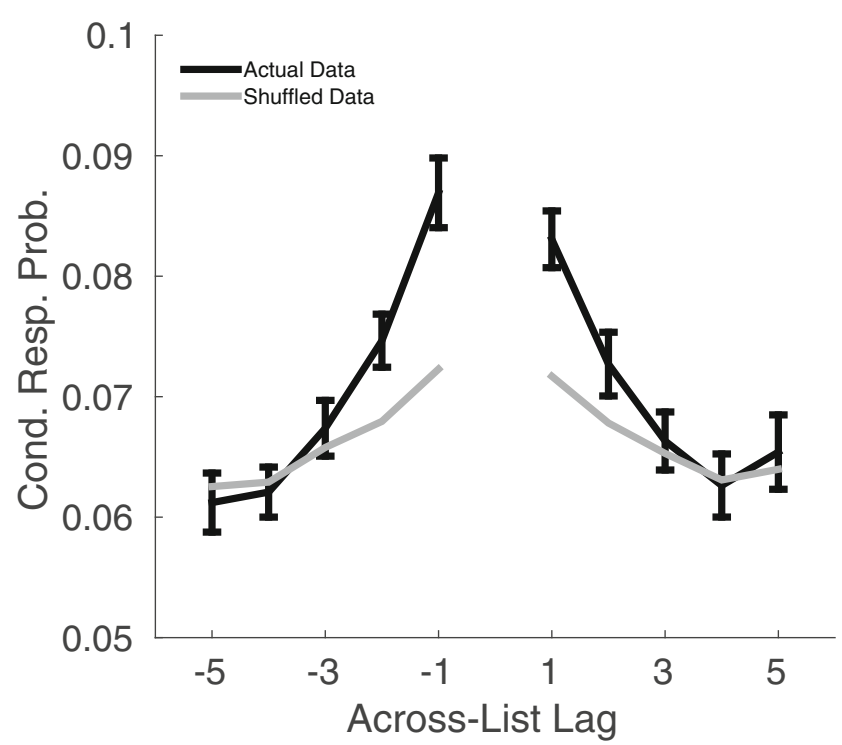

Fig. 5 Across-list transitions during final free recall show a contiguity effect. The black curve shows the conditional response probabilities computed from the actual data. The gray curve shows the conditional probability from surrogate data in which the order of recalls are randomly shuffled. The across-list contiguity effect is larger in the actual data than in the surrogate data. Data are from PEERS Experiments 1-3. Error bars are 95\% within-subject confidence intervals (Loftus \& Masson, 1994) 
that the same items could not be matched and the pairs must come from different lists. A CRP was then calculated from that shuffled data using the methods described above. This was done 10,000 times for each final free recall session, and then averaged across sessions within a subject, and then across subjects. Although these surrogate data, shown as the solid gray line in Fig. 5, do show a small contiguity effect, it cannot account for the large effect seen in the actual data. ${ }^{2}$

\section{Finding 34: Contiguity outside the lab}

Cortis Mack et al. (2017) tested for contiguity over even longer time scales by using a smart phone application to present items at a rate of 1 word per hour as subjects went about their day. A free recall test following 1 hour after the last item presentation. Even with this very long inter-item interval, there was a robust contiguity effect across three separate experiments and a variety of list lengths. These results provide strong evidence that contiguity is not limited to short time scales.

Perhaps the strongest test of whether contiguity arises at long time scales is to assess whether people encode information about temporal distance as they live their daily lives, incidentally laying down weeks and years of memories. Does recall of autobiographical memories show a contiguity effect? People can reconstruct the order of real world events (e.g., the sequence of events on September 11), and the pattern of order errors shows a clear temporal gradient around the correct position that is remarkably similar to the pattern seen in laboratory list learning tasks (Altmann, 2003). In these studies, subjects were explicitly asked to reconstruct the order of events. Does temporal information influence the recall order when subjects are free to recall autobiographical memories in any order?

Moreton and Ward (2010) asked subjects to free recall events that had occurred in their lives within the last 5 weeks, 5 months, or 5 years. Within each targeted recallperiod, subjects showed a contiguity effect, a tendency to make recall transitions between events that were within the same relative retention interval (e.g., upon recalling

\footnotetext{
${ }^{2}$ It has been suggested that the across-list contiguity effect in final free recall may be due to prior-list intrusions and not to temporal associations (Hintzman, 2016). That is, if when originally recalling list $l$, subjects intrude an item from list $l-n$, they may form new associations between list $l$ items and list $l-n$ items. Then, during final free recall, these new intrusion-mediated associations would drive across-list transitions. This is implausible given that intrusions are quite rare and unlike the contiguity effect which extends to lags of 5 , intrusions show a very steep recency effect (on average, less than 0.3 of an item per list in the PEERS data, with most coming from no more than 2 lists back; Healey \& Kahana, 2016). More to the point, the entire explanation is based on assuming that subjects form associations between temporally contiguous items during recall, despite there being no incentive to form such associations.
}

an event from 3 weeks/months/years ago, they were more likely to transition to recalling another event that occurred 3 weeks/months/years ago than one that had occurred 2 or 4 weeks/months/years ago). A limitation of this study is that it potentially confounds semantic similarity with temporal distance (Hintzman, 2016). For example, events that occur during temporally-proximate periods of your life are more likely to involve similar people and places than events that occur during more temporally-distant periods. Memorable events are also likely to occur in bursts (e.g., the various moments in your child's first year of life, or the fist few months in a new job or city) which can create an artificial contiguity effect in the same way autocorrelated variation in encoding efficiency can (see above)—if most events are separated by short lags, short lags will tend to be overrepresented in the recall sequence.

Uitvlugt and Healey (in press) attempted to address these issues by asking people to recall news stories from the 2016 presidential election campaign (Experiment 1) or the first four months of 2018 (Experiment 2). Subjects were asked to recall events from these time periods, in any order they wanted, by writing a headline to describe each recalled story. Because these events are public knowledge, not autobiographical, they can be dated precisely and their semantic similarity can be measured (in Experiment 1 by having many crowd-sourced raters judge the similarity of the headlines involved in each transition and in Experiment 2 by running Latent Semantic Analysis on the text of published accounts of the events). Even after controlling for the influences of both the distribution of possible lags and the confound between lag and semantic similarity, subjects showed a strong bias to transition among events that had appeared in the news within days of each other.

Although, to our knowledge, Moreton and Ward (2010) and Uitvlugt and Healey (in press) are the only studies to examine the contiguity effect in real world memories using behavioral measures, Nielson et al. (2015) examined contiguity in the neural representations of autobiographical events. They had subjects wear "lifelogging" cameras and GPS devices for a month and then had them recall specific events, cued by pictures from the camera, while undergoing MRI scans. For each pair of events, they computed the similarity between their neural representations and found that this similarity was robustly correlated with the temporal distance separating the events. That is, events that occurred in the same day had neural representations that were more similar to each other than did events that occurred in the same week, which in turn had more similar neural representations than events that occurred in the same month. This was true even after controlling for the spatial distance between the events. 


\section{Theoretical implications}

In these final sections we condense the 34 wide-ranging findings reviewed above into three key characteristics of the contiguity effect. In doing so we point to several open questions. We end by asking which cognitive mechanisms are likely to produce these key characteristics.

\section{Key characteristics of temporal contiguity}

Automaticity We have seen that the temporal contiguity effect is ubiquitous in free recall. It is modulated to varying degrees by many factors, but eliminated by none of them. The effect emerges in the other classic memory paradigms as well (serial recall, recognition, and paired associates learning). It also emerges in errors in free recall, paired associates, and serial recall. It emerges on surprise memory tests. And it emerges outside the lab in the recall of both autobiographical memories and memory for world events. Taken together, this pattern of results suggests that the memory system automatically encodes information about temporal proximity, regardless of the details of the current task and even when there is no expectation that temporal information will be helpful on a later memory test. Moreover, the memory system tends to use this information to guide memory search, even when other associative dimensions (like semantic similarity or presentation modality) are available to support recall.

Although the existing data are quite clear on this point, the scope of the existing data is limited. Almost all of the studies reviewed here are word-list learning tasks, and almost all of those use lists of words with minimal semantic structure. Those studies that have added some semantic structure to lists have found contiguity to be present at reduced levels. This raises the question of how important temporal contiguity is when encoding and searching for memories that have rich similarity structures along a variety of dimensions (e.g., semantic, spatial, perceptual, etc.). Some work, such as that showing contiguity in autobiographical memory, suggest that temporal proximity is important when recalling richer memories, but this literature is in its infancy. An important target for future work is to explore how different associative dimensions interact and determine whether temporal proximity enjoys a privileged status in the similarity structure of memory.

Time scale similarity In most free recall studies, items are separated by fractions of a second. In CDFR items are separated by multiple seconds. In studies of final free recall, lists are separated by minutes. In the Cortis Mack et al. (2017) study presenting items on subjects' phones, items were separated by hours. In the real world studies of Moreton and Ward (2010) and Uitvlugt and Healey (in press) events were separated by days, weeks, months, and even years. Robust temporal contiguity effects have been documented at all of these time scales. This suggests that the temporal contiguity effect, and the mechanisms that produce it, are at least approximately time scale invariant.

Exactly how invariant is the contiguity effect to changes in time scale? The data in Fig. 21 show a somewhat smaller effect in CDFR than in immediate free recall. Similarly, as noted by Howard et al. (2015), the contiguity effect observed in final free recall is shallower and less asymmetric than that observed in immediate free recall. Uitvlugt and Healey (in press) also found that contiguity in recall of news events was close to symmetric and that the magnitude of the effect was different for events spread out over two years versus four months. These observations suggest that the effect may not be precisely time scale invariant. But comparing lag-CRPs across task conditions, studies, and stimuli type is complicated by variations in overall recall level-as discussed in the section on autocorrelation in goodness of encoding, differences in the shape of the CRP could be due to differences in item availability rather than the strength of temporal associations. To our knowledge, there has been no systematic analysis of the contiguity effect across multiple time scales that controls for item availability. Such an analysis will be needed to adjudicate between models that are truly time scale invariant (e.g., Howard et al., 2015; Shankar \& Howard, 2012) and those that are merely approximately invariant (e.g., Farrell, 2012; Lohnas, Polyn, \& Kahana, 2015).

Forward asymmetry The contiguity effect in free recall has a pronounced forward asymmetry. This asymmetry is highly robust-all of the effects in Fig. 2 show it. Any theory of episodic memory encoding and search must be able to account for this regularity.

But is forward asymmetry a necessary consequence of the mechanisms that produce contiguity? The data are less clear on this point. In final free recall, the across-list contiguity effect (Fig. 5) is not forward-asymmetric (see also Howard et al., 2008). Forward asymmetry was found by Cortis Mack et al. (2017) when items were separated by hours, but was not found consistently by Uitvlugt and Healey (in press) when events were separated by days and weeks. This might suggest that time scale has different effects on the magnitude of the contiguity effect versus the magnitude of the asymmetry effect (consistent with the prediction of some models, Howard, 2004). Thus a better understanding of the factors that influence asymmetry is an important target for future work. 


\section{Contiguity generating mechanisms}

We will consider six mechanisms commonly found in contemporary models of episodic recall: associative chaining, short-term memory, positional coding, chunking, contextual dynamics, and control processes. The mechanisms are not all mutually exclusive. Indeed, many models include several of them, such as contextual dynamics and shortterm memory (e.g., Davelaar, Goshen-Gottstein, Ashkenazi, Haarmann, \& Usher, 2013; Lehman \& Malmberg, 2005) or contextual dynamics and chunking (Farrell, 2012). Nonetheless, it is useful to ask which of the mechanisms provide the most comprehensive and parsimonious account of the available data. Therefore, for each mechanism we will describe how it can facilitate the encoding of temporal proximity and ask whether it can account for the three key characteristics of contiguity we outlined above. We track the results in Table 2 .

Associative chaining Associative chaining models assume that new associations form directly between successive items during study (Lewandowsky \& Murdock, 1989; Humphreys et al., 1989; Solway et al., 2012). That is, chaining directly encodes temporal proximity by forming associations between temporally adjacent items. Insofar as these models hold chaining to be a fundamental property of the memory system, they naturally account for the apparent automaticity of the contiguity effect. But if the chain links only adjacent items (i.e., nearest neighbor chaining Lewandowsky \& Murdock, 1989; Metcalfe \& Murdock, 1981), the result would be a very steep, and symmetric, contiguity effect such that recalling item $i$ would almost always be followed by recalling either $i+1$ or $i-1$. Elaborated versions of chaining may be able to produce a smooth lag-CRP by allowing associations between nonadjacent items (Solway et al., 2012) or by using blurred

Table 2 Which mechanisms can account for the key characteristics of the temporal contiguity effect

\begin{tabular}{llll}
\hline Mechanism & Automaticity & $\begin{array}{l}\text { Time scale } \\
\text { similarity }\end{array}$ & $\begin{array}{l}\text { Forward } \\
\text { asymmetry }\end{array}$ \\
\hline Associative chaining & $\checkmark$ & $\times$ & $\times$ \\
Short-term memory & $\checkmark$ & $\times$ & $\checkmark$ \\
Positional coding & $\checkmark$ & $\checkmark$ & $\ominus$ \\
Chunking & $\checkmark$ & $\ominus$ & $\checkmark$ \\
Contextual dynamics & $\checkmark$ & $\ominus$ & $\checkmark$ \\
Control processes & $\times$ & $\times$ & $\times$ \\
\hline
\end{tabular}

$\checkmark=$ The mechanism provide a natural account. $\ominus=$ The mechanism can provide an account given reasonable additional assumptions. $x=$ The model cannot provide an account even with reasonable modifications representations as recall cues (so they provided evidence for items at multiple lags; e.g., Lewandowsky \& Murdock, 1989). Time scale similarity and forward asymmetry pose a greater challenge for chaining. Time scale similarity is a problem because chaining offers no explanation of how direct links could form between lists separated by minutes in final free recall or life events separated by weeks in autobiographical memory-one would have to postulate multiple chains, each with a different timescale. Asymmetry is a problem because most chaining models, especially those that use correlation to form associations and convolution to retrieve items (e.g., Lewandowsky \& Murdock, 1989) embody a holistic (Gestalt) view of associations whereby the forward and backward associations are symmetric (Caplan et al., 2014; Kahana, 2002), without ad hoc modification it would be difficult for such a model to produce a forward asymmetric chain.

Short-term memory Many models assume that when items spend time together in short-term memory (or working memory), new long-term associations form between them (Cowan et al., 2013), with the strength of the association being a function of how much time they spend together (Raaijmakers \& Shiffrin, 1981). If items presented close together in a list tend to spend more time co-occupying short-term memory than items presented further apart in the list (e.g., Phillips, Shiffrin, \& Atkinson, 1967), a contiguity effect will naturally be produced (Kahana, 1996). Moreover, on the assumption that passing through short-term memory is the only way for items to get encoded in long-term memory (Atkinson \& Shiffrin, 1968), contiguity in immediate recall would be automatic and ubiquitous. But shortterm memory can not easily account for contiguity between events that were separated by several seconds of filled distraction (Howard \& Kahana, 2002a), much less between events separated by hours or days. At shorter time scales, several dual-store models have been shown to produce a contiguity effect that closely agrees with the forwardasymmetric shape of the contiguity effect observed in immediate and delayed free recall (Kahana, 1996; Davelaar et al., 2005; Lehman \& Malmberg, 2013). Thus short-term memory can automatically produce forward-asymmetric contiguity at short time scales, but additional mechanisms are needed to explain long-range contiguity.

One such mechanism could be a reminding process. Reminding refers to the phenomenon of a new event spontaneously triggering retrieval of an earlier event (e.g., Hintzman, 2011; Wahlheim \& Jacoby, 2013). To illustrate, imagine if the semantically related words $d o g$ and cat both appeared in a list separated by some lag. Presentation of $d o g$ could remind the subject that cat had been studied earlier, allowing the two to co-occupy short-term memory and thus form a new episodic link that increases the probability they 
will be recalled together. In situations where the semantic similarity between two events tends to be positively correlated with the temporal lag separating those events, reminding could contribute to a contiguity effect even at long time scales. Uitvlugt and Healey (in press) found evidence that just such a positive correlation between similarity and lag exists in real-world news stories and contributes to, but does not fully explain, the contiguity effect. A reminding account has more difficulty, however, with the long-range contiguity effects observed in continual distractor free recall and final free recall where lists are randomly generated such that, across subjects, there should be no correlation between similarity and lag.

Positional coding Positional coding models (e.g., Burgess \& Hitch, 2006; Farrell \& Lewandowsky, 2002; Lewandowsky \& Farrell, 2000; Oberauer, Lewandowsky, Farrell, Jarrold, \& Greaves, 2012) assume that each list item becomes associated with a representation that codes the item's position in the input sequence and that these codes can be used as cues during memory search (for a review see Caplan, 2015). These position codes can be explicit representations of list position (e.g., Farrell \& Lewandowsky, 2002) or they can be representations of temporal distance from the present moment (Brown et al., 2007). If nearby positional codes are similar and thus confusable (Brown et al., 2007; Oberauer et al., 2012; Farrell \& Lewandowsky, 2002), cuing with positional code $i$ will activate not just the item from position $i$ but also items associated with other positions in a decreasing function of $|i+l a g|$, producing a contiguity effect. Provided that events are automatically associated with position codes whenever episodic memories are formed, even incidentally, positional coding could account for the automaticity of the contiguity effect. Time scale similarity is also a natural prediction of models in which the psychological distance between the present moment and temporal markers is logarithmically compressed (Brown et al., 2007). With the reasonable added assumption that items occupy a temporally extended region of the time line (rather than a single point), these time scale similar models would also predict forward asymmetry (Brown et al., 2008).

Chunking Chunks, or groups, can be formed by associating each item with a superordinate representation (e.g., Anderson \& Matessa, 2012; Farrell, 1997). A recent implementation of chunking (Farrell, 2012) includes two key mechanisms that produce contiguity. First, items separated by small lags in the study list are more likely to be in the same group than items separated by large lags, thus contiguity will naturally arise by recalling items within a group before moving on to another group. Second, the model incorporates a positional coding mechanism such that each item is associated with a within-group positional code, and these codes are similar for temporally proximate positions. Therefore, the model generates contiguity for much the same reason a positional coding model does: cuing with positional code $i$ will activate item $i$ but also the other items in the group as a decreasing function of their lag from item $i$. By itself, chunking would not predict time scale similarity. But the Farrell (2012) model posits a hierarchy of chunks (e.g., items are grouped into list, and within lists into chunks), thus the model could conceivably produce contiguity at a long time scales by adding levels to this hierarchy with increasingly coarse time scales (e.g., day-level chunks, week-level chunks, etc.). Moreover, because items within a cluster are recalled by cuing with position markers in forward serial order, the model also produces a forward asymmetry.

Contextual dynamics Many models assume that new events become associated with the current state of an internal context representation that continually drifts through a high-dimensional space, with the accessibility of a particular memory depending on its association with the current state of context (McGeoch, 1932; Underwood, 1945; Estes, 1955; Murdock, 1997; Mensink \& Raaijmakers, 1988; Bower, 1967; Tulving, 1972). Under retrieved context models (for the most recent implementations see, Howard et al., 2015; Lohnas et al., 2015), context drift is not random, but is driven by the cognitive representations activated by newly experienced events (e.g., studying, or recalling, a list item). Because of contextual drift, items that were presented near together in time will be associated with more similar states of context than will items presented farther apart in time. Thus, searching memory by using the context associated with the just-retrieved item as a cue automatically produces a contiguity effect. These models also naturally predict time scale similarity because they use a competitive retrieval rule that is sensitive to the relative similarity of contextual states (i.e., states of context separated by 1 second are more similar than states separated by 2 seconds, but states of context separated by 1 min are also more similar than states separated by $2 \mathrm{~min}$ ). But to show time scale similarity at scales ranging from seconds to weeks (or longer), these models must be extended to include multiple context representations that drift at different rates (Howard et al., 2015). Retrieved context models naturally predict asymmetry because each new item adds its cognitive representation to context which then becomes associated with items presented after (but not before) it. Thus, during retrieval, the context state of a just-recalled item is a better cue for items at positive lags than for items at negative lags (Howard \& Kahana, 2002a).

Control processes Control processes (Lehman \& Malmberg, 2013; Atkinson \& Shiffrin, 1968) allow us to implement various ad hoc encoding and retrieval strategies to meet 
the demands of particular tasks (e.g., Delaney \& Knowles, 2005; Unsworth, 2016). Some of these strategies could produce a contiguity effect (Hintzman, 2016). For example, subjects may link successive list items together to tell a story (Delaney \& Knowles, 2005), or they might employ the method of loci (Bouffard et al., 2018), linking items to a pre-memorized sequence of locations. These strategies entail attending to the order of presentation and recapitulating it during recall: both would produce a contiguity effect. Such strategies almost certainly contribute to the contiguity effect observed in standard free recall tasks, but it is difficult to see how they can provide a parsimonious account of the apparent automaticity of the effect. Particularly problematic are cases where subjects have no reason to engage in a contiguity-generating strategy, such as when contiguity is observed under incidental encoding, in across-pair errors in paired associate learning, in across-list transitions in final free recall, and in recall of real-world events. Similarly, it is unclear how strategic control processes can provide a unified account of contiguity across time scales. Certain strategies could produce a forward asymmetry (the method of loci, for example) under the limited range of situations where subjects would choose to employ the strategy.

Reviewing Table 2, we see that several of the mechanisms are unlikely to provide a comprehensive account of the contiguity effect. Chaining, short-term memory, and strategic control processes are all unable to account for the time scale similarity of the effect. Chaining and strategic control processes also do not provide a natural account of forward asymmetry. And strategic control processes cannot account for the ubiquity and seeming automaticity of the contiguity effect. This does not mean that these processes never contribute to the contiguity effect in particular studies. But it does mean that a comprehensive model of the contiguity effect must include additional mechanisms. The remaining three mechanisms are good candidates. Contextual dynamics, the most sophisticated implementations of positional coding, and hierarchical chunking are all consistent with the three key characteristics of the contiguity effect given reasonable assumptions. It is possible that a complete model of the contiguity effect will have to include all three. But this would be an unparsimonious conclusion at this point. Instead, we suggest that the 34 effects reviewed here can serve as a set of benchmarks for modeling work aimed at determining whether any of these mechanisms can provide a quantitatively precise account of the available data.

\section{Summary and final remarks}

Memory search unfolds as a series of retrievals, with one retrieved memory triggering retrieval of another. The temporal distance between events helps drive this chain of retrievals: upon successfully retrieving one event, subjects have a strong bias to next retrieve an event that occurred close in time to the just-recalled event. Here, we have examined how this contiguity effect is influenced by a range of variables. We found that although many factors influence the magnitude of the contiguity effect, few, if any, eliminate it.

We saw that the contiguity effect is present in essentially all individuals and its magnitude is positively correlated with both recall success and general intellectual ability. Within individuals, a robust contiguity effect is observed on their very first free recall trial and remains even after they gain weeks of experience with the task. Moreover, the effect cannot be explained by within-individual variation in goodness of encoding. Contiguity is robust to many different parameters of the free recall task, including list length, presentation rate, modality of presentation, modality of recall responses, retention interval, inter-item delay, encoding task, and the semantic associations among list items.

The contiguity effect also generalizes beyond accurate retrievals in free recall and is observed even in situations where it would be difficult or counterproductive to deliberately encode temporal distance. These include across-list transitions in final free recall, intrusion errors in free recall, order errors in serial recall, across-pair intrusions in paired associate learning, and compound-cuing in recognition. Finally, we discussed several studies that showed contiguity effects in the recall of real-life memories formed outside the lab.

We have shown that a successful model of contiguity effects in episodic memory must encode information about temporal distance at multiple time scales. The mechanisms that encode this information about temporal distance should generalize across tasks, encoding manipulations, and materials, suggesting a degree of automaticity. Among the models we have reviewed, the data appear most consistent with either retrieved-context models, some positional coding and hierarchical-clustering models, or hybrid models that combine these mechanisms.

Author Note This research was funded by National Institutes of Health Grants AG048233 and MH55687. We thank Patrick Crutchley, Jonathan Miller, and Isaac Pedisich for assistance with programming the experiments and Adam Broitman, Elizabeth Crutchley, Kylie Hower, Joel Kuhn, and Logan O'Sullivan for help with data collection. We thank Jeremy Caplan and Marc Howard for helpful comments on the manuscript.

\section{Appendix A: Penn electrophysiology of encoding and retrieval study}

The Penn Electrophysiology of Encoding and Retrieval Study (PEERS) aims to assemble a large database on the 
electrophysiological correlates of memory encoding and retrieval (Healey \& Kahana, 2014; Healey et al., 2014; Lohnas \& Kahana, 2014, 2013; Miller et al., 2012; Healey \& Kahana, 2016). Here, we report data from Experiments 1 and 4. We describe the methods of those experiments in detail (for full details on the design of PEERS, see Healey \& Kahana, 2014; Lohnas \& Kahana, 2013).

\section{Subjects}

The present analyses are based on the subjects who had began PEERS as of April 2015. The sample included 466 subjects who completed an introductory session. Of these, a subset consisting of 172 younger adults (age range: 18-30 years) and 38 older adults (age range: 61-85 years) completed all sessions of Experiment 1 (see Healey \& Kahana, 2016, for full details on the older adult sample). Of the younger adult sample, 31, the practiced group, also completed at least 12 sessions of Experiment 4. A second subset of 20 younger adults, the naïve group, completed at least 12 sessions of Experiment 4 but had not participated in Experiments 1-3. All subjects were right-handed native English speakers. The methods for this study were approved by the University of Pennsylvania Institutional Review Board.

\section{PEERS introductory session}

Prospective subjects completed a introductory session to introduce them to the free recall task and ensure they did not make an excess of eye movements during item presentation epochs (to avoid muscle artifacts making EEG data unusable) and had a probability of recall less than 0.8 (to avoid subject's being at ceiling even before practice). The introductory session consisted of 12 lists of 16 words presented one at a time on a computer screen for $1600 \mathrm{~ms}$, followed by a jittered (i.e., variable) inter-stimulus interval of 800-1200 ms (uniform distribution).

The final word of each list was followed by a distractor period in which subjects answered math problems of the form $A+B+C=$ ?, where $A, B$, and $C$ were positive, single-digit integers, though the answer could have been one or two digits. When a math problem was presented on the screen, the subject typed the sum as quickly as possible. The task was self-paced and lasted a minimum of $20 \mathrm{~s}$ although if the subject was working on a problem when the time expired, they were allowed to complete that problem.

\section{PEERS Experiment 1}

Subjects performed a free recall experiment consisting of 1 practice session and 6 subsequent experimental sessions. Each session consisted of 16 lists in which 16 words were presented one at a time on a computer screen. Each study list was followed by an immediate free recall test. At the end of each session, there was a recognition test and, for a subset of sessions, a final free recall test.

Words were either presented concurrently with a task cue, indicating the judgment that the subject should make for that word, or with no encoding task. The two encoding tasks were a size judgment ("Will this item fit into a shoebox?") and an animacy judgment ("Does this word refer to something living or not living?"), and the current task was indicated by the color and typeface of the presented item. There were three conditions: no-task lists (subjects did not have to perform judgments with the presented items), single-task lists (all items were presented with the same task), and task-shift lists (items were presented with either task). List and task order were counterbalanced across sessions and subjects.

Each word was drawn from a pool of 1638 words. Lists were constructed such that varying degrees of semantic relatedness occurred at both adjacent and distant serial positions. Semantic relatedness was determined using the Word Association Space (WAS) model described by Steyvers et al. (2004). WAS similarity values were used to group words into four similarity bins (high similarity: $\cos \theta$ between words $>0.7$; medium-high similarity, $0.4<$ $\cos \theta<0.7$; medium-low similarity, $0.14<\cos \theta<0.4$; low similarity, $\cos \theta<0.14)$. Two pairs of items from each of the four groups were arranged such that one pair occurred at adjacent serial positions and the other pair was separated by at least two other items.

For each list, there was a $1500 \mathrm{~ms}$ delay before the first word appeared on the screen. Each item was on the screen for $3000 \mathrm{~ms}$, followed by a jittered (i.e., variable) interstimulus interval of 800-1200 ms (uniform distribution). If the word was associated with a task, subjects indicated their response via a keypress. After the last item in the list, there was a jittered delay of 1200-1400 ms, after which a tone sounded, a row of asterisks appeared, and the subject was given 75 seconds to attempt to recall aloud any of the justpresented items. If a session was randomly selected for final free recall, following the immediate free recall test from the last list, subjects were shown an instruction screen for final free recall, telling them to recall all the items from the preceding lists. After a 5 second delay, a tone sounded and a row of asterisks appeared. Subjects had $5 \mathrm{~min}$ to recall any item from the preceding lists. After either final free recall or the last list's immediate recall test, there was a recognition test, which is not considered here (for full details, see Healey \& Kahana, 2016; Lohnas \& Kahana, 2013).

\section{PEERS Experiment 2}

Experiment 2 was identical to Experiment 1 except as described below. Each of the 6 non-practice sessions 
consisted of 12 study lists of 16 words. Distractor tasks consisted of answering math problems of the form $A+$ $B+C=$ ?, where $A, B$, and $C$ were positive, singledigit integers, though the answer could have been one or two digits. When a math problem was presented on the screen, the subject typed the sum as quickly as possible. The task was self-paced, such that a subject may have been presented with, but not responded to, a problem at the end of the distraction interval. Subjects were given a monetary bonus based on the speed and accuracy of their responses. In the first two trials, subjects performed free recall with one trial having a distractor period following the last word presentation for $8 \mathrm{~s}$. For the other of the first two trials, subjects performed an $8 \mathrm{~s}$ distractor period prior to and following each word presentation. In the remaining 10 trials, subjects performed free recall with 5 possible time durations for the between-item and end-of-list distractor tasks. As listed here, the first number indicated the betweenlist distractor duration and the second number indicated the end-of-list distractor, both in seconds: $0-0,0-8,0-16,8-$ 8, 16-16. A $0 \mathrm{~s}$ distractor refers to the typical, non-filled duration intervals as described for Experiment 1. Within each session, half of the lists were randomly chosen to be task-switch lists, and the other half were single-task lists.

The first session in this experiment was designed to introduce subjects to the math task. This session was identical to the experimental sessions except as described below. This session contained 14 lists, the first 4 of which were 2 lists of 8-8 and 2 lists of 0-8, with the order randomly chosen. These lists were all single-task lists, two each of each judgment type randomly chosen. The remaining 10 lists had distractor tasks as in the experimental sessions. All of these lists were single-task lists, with half randomly chosen to be of one task. This session always contained a final free recall period.

\section{PEERS Experiment 3}

Experiment 3 used the externalized recall (ER) procedure (Kahana et al., 2005a; Zaromb et al., 2006; Unsworth et al., 2009; Unsworth \& Brewer, 2010) to obtain more complete information on subjects' tendency to commit intrusions during recall and on their ability to distinguish between intrusions and correct responses. In Experiment 3, 96 subjects were given externalized recall instructions and the remaining subjects were given standard free recall instructions.

In the ER procedure, after subjects had become familiar with the standard free recall instructions, we asked them to say out loud all words that came to mind at the time of test, even if they thought those words did not occur in the most recent list, which they are explicitly attempting to recall. To separately examine the internal censoring process during recall, we asked subjects to indicate when they have recalled an item they believe was not on the most recent list by pressing the spacebar immediately following recall of that item.

The ER procedure was introduced in a preliminary session which began identically to Experiment 1. After the third list, instructions appeared on the computer screen indicating that subjects should additionally say aloud every time a specific, salient word came to mind while performing free recall. Subjects were also instructed to press the spacebar immediately following recall of an intrusion or repetition. An experimenter sat in with the subject during this session to ensure that the subject understood these instructions. Following this preliminary session, subjects performed five experimental sessions with methods identical to Experiment 1 except that subjects were given ER instructions at the beginning of each free recall session. Three out of the six (one practice and five experimental) sessions were randomly chosen to have final free recall, and each of the final free recall periods also began with the ER instruction.

\section{PEERS Experiment 4}

Subjects performed a delayed free recall experiment consisting of 24 experimental sessions. Each session consisted of 24 lists of 24 words that were presented one at a time on a computer screen. Each study list was followed by a $24 \mathrm{~s}$ distractor-filled delay before a free recall test.

Each session requires $24 \times 24=576$ words. For each subject, a unique word pool of 576 words was drawn from the larger 1638-word pool used in Experiment 1. This same 576-word pool was used to generate the lists for each session 1-23. That is, subjects saw the same set of words across sessions 1-23, but randomly assigned to different lists in each session. The 24th session introduced some new words, which were drawn from the remaining words in the larger 1638-word pool. Specifically, the 24th session included 8 lists composed of 8 old/16 new words, 8 lists composed of 12 old/12 new words, and 8 lists composed of $16 \mathrm{old} / 8$ new words. Within all sessions, words were randomly assigned to lists with the following constraints: Lists were constructed such that varying degrees of semantic relatedness occurred at both adjacent and distant serial positions. WAS similarity values were used to group words into four similarity bins using the same procedure described for Experiment 1. Two pairs of items from each of the four groups were arranged such that one pair occurred at adjacent serial positions and the other pair was separated by at least two other items.

For all lists, there was a $1500 \mathrm{~ms}$ delay before the first stimuli appeared on the screen. For a random half of the lists in each session (excluding list 1), subjects completed 
a pre-list distractor task for $24 \mathrm{~s}$ before presentation of the first word, with a 800-1200 ms (uniform distribution) jittered delay between the last distractor problem and the presentation of the first list word. Each word was on the screen for $1600 \mathrm{~ms}$, followed by a jittered (i.e., variable) inter-stimulus interval of 800-1200 ms (uniform distribution). Following the presentation of the last word in each list, subjects performed a distractor task for $24 \mathrm{~s}$. Both the pre-list and post-list distractor task consisted of answering math problems of the form $A+B+C=$ ?, where $A, B$, and $C$ were positive, single-digit integers, though the answer could have been one or two digits. When a math problem was presented on the screen, the subject typed the sum as quickly as possible. The task was selfpaced, such that a subject may have been presented with, but not responded to, a problem at the end of the distraction interval. Subjects were given a monetary bonus based on the speed and accuracy of their responses. After the post-list distractor task, there was a jittered delay of 1200-1400 ms, after which a tone sounded, a row of asterisks appeared, and the subject was given $75 \mathrm{~s}$ to attempt to recall aloud any of the just-presented items.

\section{Intelligence testing}

The Wechsler Adult Intelligence Scale (WAIS) IV (Wechsler, 2008) was administered to 135 of the younger adults who completed Experiment 1. WAIS testing was conducted by a trained clinical psychologist in one-on-one sessions after completing all free recall sessions. We omitted the working memory index of the WAIS as we were concerned that subjects' extensive practice with free recall would artificially inflate their scores.

Publisher's Note Springer Nature remains neutral with regard to jurisdictional claims in published maps and institutional affiliations.

\section{References}

Altmann, E. M. (2003). Reconstructing the serial order of events: A case study of september 11, 2001. Applied Cognitive Psychology, 17(9), 1067-1080.

Anderson, J. R., \& Matessa, M. (1997). A production system theory of serial memory. Psychological Review, 104, 728-748.

Atkinson, R. C., \& Shiffrin, R. M. (1968). Human memory: A proposed system and its control processes. In Spence, K. W., \& Spence, J. T. (Eds.) The psychology of learning and motivation, (Vol. 2, pp. 89-105). New York: Academic Press.

Averell, L., Prince, M., \& Heathcote, A. (2016). Fundamental causes of systematic and random variability in recognition memory. Journal of Memory and Language, 88, 51-69.

Bean, R. R., Bernhardt, L. V., Brimmeier, L. L., Smith, R. L., Zerka, J. N., Uitvlugt, M. G., \& Healey, M. K. (2017). Temporal contiguity is modulated, but not eliminated, by orthographic distinctivness. Poster presented at Mid-Michigan Symposium for Undergraduate Research Experiences. East Lansing, MI. Retrieved from https://cbcc.psy.msu.edu/presentations/ UURAF2018.pdf.

Bhatarah, P., Ward, G., \& Tan, L. (2006). Examining the relationship between free recall and immediate serial recall: The effect of concurrent task performance. Journal of Experimental Psychology: Learning, Memory, and Cognition, 32(2), 215-229.

Bjork, R. A., \& Whitten, W. B. (1974). Recency-sensitive retrieval processes in long-term free recall. Cognitive Psychology, 6, 173189.

Bouffard, N., Stokes, J., Kramer, H. J., \& Ekstrom, A. D. (2018). Temporal encoding strategies result in boosts to final free recall performance comparable to spatial ones. Memory \& Cognition, $46(1), 17-31$.

Bousfield, W. A., Sedgewick, C. H., \& Cohen, B. H. (1954). Certain temporal characteristics of the recall of verbal associates. American Journal of Psychology, 67, 111-118.

Bower, G. H. (1967). A multicomponent theory of the memory trace. In Spence, K. W., \& Spence, J. T. (Eds.) The psychology of learning and motivation: Advances in research and theory (Vol. 1, pp. 229-325). New York: Academic Press.

Brown, G. D. A., Neath, I., \& Chater, N. (2007). A temporal ratio model of memory. Psychological Review, 114(3), 539-576.

Brown, G. D., Chater, N., \& Neath, I. (2008). Serial and free recall: Common effects and common mechanisms? A reply to Murdock.

Burgess, N., \& Hitch, G. J. (2006). A revised model of short-term memory and long-term learning of verbal sequences. Journal of Memory and Language, 55, 627-652.

Burns, D. J. (1996). The item-order distinction and the generation effect: The importance of order information in long-term memory. The American Journal of Psychology, 109(4), 567.

Caplan, J. B. (2015). Order-memory and association-memory. Canadian Journal of Experimental Psychology, 69(3), 221.

Caplan, J. B., Glaholt, M., \& McIntosh, A. R. (2006). Linking associative and list memory: Pairs versus triples. Journal of Experimental Psychology: Learning, Memory \& Cognition, 32(6), $1244-1265$

Caplan, J. B., Rehani, M., \& Andrews, J. C. (2014). Associations compete directly in memory. The Quarterly Journal of Experimental Psychology, 67(5), 955-978.

Castel, A. D. (2005). Memory for grocery prices in younger and older adults: The role of schematic support. Psychology and Aging, 20(4), 718-721.

Castel, A. D., Benjamin, A. S., Craik, F. I. M., \& Watkins, M. J. (2002). The effects of aging on selectivity and control in short-term recall. Memory and Cognition, 30(7), 1078-1085.

Cortis Mack, C., Dent, K., Kennett, S., \& Ward, G. (2015). First things first: Similar list length and output order effects for verbal and nonverbal stimuli. Journal of Experimental Psychology: Learning, Memory, and Cognition, 41(4), 1179.

Cortis Mack, C., Cinel, C., Davies, N., Harding, M., \& Ward, G. (2017). Serial position, output order, and list length effects for words presented on smartphones over very long intervals. Journal of Memory and Language, 97, 61-80.

Cortis Mack, C., Dent, K., \& Ward, G. (2018). Near-independent capacities and highly constrained output orders in the simultaneous free recall of auditory-verbal and visuo-spatial stimuli. Journal of Experimental Psychology: Learning, Memory, and Cognition, 44(1), 107-134.

Cowan, N., Donnell, K., \& Saults, J. S. (2013). A listlength constraint on incidental item-to-item associations. Psychonomic Bulletin and Review, 20(6), 1253-1258. https://doi.org/10.3758/s13423-013-0447-7 
Davelaar, E. J., Goshen-Gottstein, Y., Ashkenazi, A., Haarmann, H. J., \& Usher, M. (2005). The demise of shortterm memory revisited: Empirical and computational investigations of recency effects. Psychological Review, 112, 3-42. https://doi.org/10.1037/0033-295X.112.1.3

Davis, O. C., Geller, A. S., Rizzuto, D. S., \& Kahana, M. J. (2008). Temporal associative processes revealed by intrusions in paired-associate recall. Psychonomic Bulletin \& Review, 15(1), 64-69.

Delaney, P. F., \& Knowles, M. E. (2005). Encoding strategy changes and spacing effects in the free recall of unmixed lists. Journal of Memory and Language, 52(1), 120-130.

Estes, W. K. (1955). Statistical theory of distributional phenomena in learning. Psychological Review, 62, 369-377. https://doi.org/10. 1037/h0046888

Farrell, S., \& Lewandowsky, S. (2002). An endogenous distributed model of ordering in serial recall. Psychonomic Bulletin \& Review, 9, 59-85. https://doi.org/10.3758/BF03196257

Farrell, S., \& Lewandowsky, S. (2008). Empirical and theoretical limits on lag recency in free recall. Psychonomic Bulletin and Review, 15, 1236-1250. https://doi.org/10.3758/PBR.15.6.1236

Farrell, S. (2012). Temporal clustering and sequencing in short-term memory and episodic memory. Psychological Review, 119(2), 223-271. https://doi.org/10.1037/a0027371

Farrell, S., Hurlstone, M. J., \& Lewandowsky, S. (2013). Sequential dependencies in recall of sequences: Filling in the blanks. Memory \& Cognition, 41, 938-952.

Gibson, B. S., Healey, M. K., \& Gondoli, D. M. (in press). Modeling the effect of attention-deficit hyperactivity disorder on episodic memory. Journal of Abnormal Psychology.

Glenberg, A. M., \& Bradley, M. M. (1979). Mental contiguity. Journal of Experimental Psychology: Human Learning and Memory, 5(2), 88-97.

Healey, M. K. (2018). Temporal contiguity in incidentally encoded memories. Journal of Memory and Language, 102, 28-40.

Healey, M. K., \& Kahana, M. J. (2014). Is memory search governed by universal principles or idiosyncratic strategies? Journal of Experimental Psychology: General, 143, 575-596. https://doi.org/ 10.1037/a0033715

Healey, M. K., \& Kahana, M. J. (2016). A four-component model of age-related memory change. Psychological Review, 123(1), 23-69. https://doi.org/10.1037/rev0000015

Healey, M. K., Crutchley, P., \& Kahana, M. J. (2014). Individual differences in memory search and their relation to intelligence. Journal of Experimental Psychology: General, 143(4), 15531569. https://doi.org/10.1037/a0036306

Hintzman, D. L. (2011). Research strategy in the study of memory: Fads, fallacies, and the search for the "coordinates of truth". Perspectives on Psychological Perspectives on Psychological Science, 6(3), 253-271.

Hintzman, D. L. (2016). Is memory organized by temporal contiguity? Memory \& Cognition, 44, 365-375.

Hintzman, D. L., \& Hartry, A. L. (1990). Item effects in recognition and fragment completion: Contingency relations vary for different subsets of words. Journal of Experimental Psychology: Learning, Memory, and Cognition, 16, 965-969.

Howard, M. W. (2004). Scaling behavior in the temporal context model. Journal of Mathematical Psychology, 48, 230-238. https://doi.org/10.1016/j.jmp.2004.03.004

Howard, M. W. (2017). Manuscript, in preparation.

Howard, M. W., \& Kahana, M. J. (1999). Contextual variability and serial position effects in free recall. Journal of Experimental Psychology: Learning, Memory, and Cognition, 25, 923-941. https://doi.org/10.1037/0278-7393.25.4.923
Howard, M. W., \& Kahana, M. J. (2002a). A distributed representation of temporal context. Journal of Mathematical Psychology, 46(3), 269-299.

Howard, M. W., \& Kahana, M. J. (2002b). When does semantic similarity help episodic retrieval? Journal of Memory and Language, 46, 85-98.

Howard, M. W., Youker, T. E., \& Venkatadass, V. (2008). The persistence of memory: Contiguity effects across hundreds of seconds. Psychonomic Bulletin \& Review, 15, 58-63. https://doi.org/10.3758/PBR.15.1.58

Howard, M. W., Sederberg, P. B., \& Kahana, M. J. (2009). Reply to Farrell \& Lewandowsky: Recency-contiguity interactions predicted by the temporal context model. Psychonomic Bulletin \& Review, 16, 973-984. https://doi.org/10.3758/PBR.16.5.973

Howard, M. W., Shankar, K. H., Aue, W. R., \& Criss, A. H. (2015). A distributed representation of internal time. Psychological Review, 122(1), 24-53. https://doi.org/10.1037/a0037840

Humphreys, M. S., Bain, J. D., \& Pike, R. (1989). Different ways to cue a coherent memory system: A theory for episodic, semantic, and procedural tasks. Psychological Review, 96, 208-233.

Jarrold, C., Hall, D., Harvey, C. E., Tam, H., Towse, J. N., \& Zarandi, A. L. (2015). What can we learn about immediate memory from the development of children's free recall? The Quarterly Journal of Experimental Psychology, 68(9), 1871-1894.

Kahana, M. J. (1996). Associative retrieval processes in free recall. Memory \& Cognition, 24(1), 103-109. https://doi.org/10.3758/ BF03197276

Kahana, M. J. (2002). Associative symmetry and memory theory. Memory \& Cognition, 30, 823-840.

Kahana, M. J., \& Caplan, J. B. (2002). Associative asymmetry in probed recall of serial lists. Memory \& Cognition, 30, 841-849.

Kahana, M. J., Howard, M. W., Zaromb, F., \& Wingfield, A. (2002). Age dissociates recency and lag recency effects in free recall. Journal of Experimental Psychology: Learning, Memory, and Cognition, 28, 530-540. https://doi.org/10.1037/0278-7393.28.3.530

Kahana, M. J., Dolan, E. D., Sauder, C. L., \& Wingfield, A. (2005a). Intrusions in episodic recall: Age differences in editing of overt responses. Journal of Gerontology: Psychological Sciences, 60, 92-97. https://doi.org/10.1093/geronb/60.2.P92

Kahana, M. J., Rizzuto, D. S., \& Schneider, A. (2005b). Theoretical correlations and measured correlations: Relating recognition and recall in four distributed memory models. Journal of Experimental Psychology: Learning, Memory, and Cognition, 31, 933-953.

Kilıç, A., Criss, A. H., \& Howard, M. W. (2013). A causal contiguity effect that persists across time scales. Journal Experimental Psychology: Learning, Memory and Cognition, 39(1), 297-303.

Kintsch, W. (1970). Models for free recall and recognition. In Norman, D. A. (Ed.) Models of human memory (pp. 331-373). New York: Academic Press.

Klein, K. A., Addis, K. M., \& Kahana, M. J. (2005). A comparative analysis of serial and free recall. Memory \& Cognition, 33, 833-839.

Lee, C. L., \& Estes, W. K. (1977). Order and position in primary memory for letter strings. Journal of Verbal Learning and Verbal Behavior, 16, 395-418.

Lehmann, M., \& Hasselhorn, M. (2010). The dynamics of free recall and their relation to rehearsal between 8 and 10 years of age. Child Development, 81(3), 1006-1020.

Lehman, M., \& Hasselhorn, M. (2012). Rehearsal dynamics in elementary school children. Journal of Experimental Child Psychology, 111(3), 552-560.

Lehman, M., \& Malmberg, K. J. (2013). A buffer model of memory encoding and temporal correlations in retrieval. Psychological Review, 120(1), 155-189. https://doi.org/10.1037/a0030851 
Lewandowsky, S., \& Farrell, S. (2000). A redintegration account of the effects of speech rate, lexicality, and word frequency in immediate serial recall. Psychological Research Psychologische Forschung, 63(2), 163-173.

Lewandowsky, S., \& Murdock, B. B. (1989). Memory for serial order. Psychological Review, 96, 25-57. https://doi.org/10.1037/0033295X.96.1.25

Loaiza, V. M., \& McCabe, D. P. (2012). Temporal-contextual processing in working memory: Evidence from delayed cued recall and delayed free recall tests. Memory \& Cognition, 40(2), 191-203.

Loftus, G. R., \& Masson, M. E. J. (1994). Using confidence intervals in within-subject designs. Psychonomic Bulletin \& Review, 1, 476-490.

Lohnas, L. J., \& Kahana, M. J. (2013). Parametric effects of word frequency effect in memory for mixed frequency lists. Journal of Experimental Psychology: Learning, Memory, and Cognition, 39(6), 1943-1946. https://doi.org/10.1037/a0033669

Lohnas, L. J., \& Kahana, M. J. (2014). Compound cuing in free recall. Journal of Experimental Psychology: Learning, Memory and Cognition, 40(1), 12-24. https://doi.org/10.1037/a0033698

Lohnas, L. J., Polyn, S. M., \& Kahana, M. J. (2015). Expanding the scope of memory search: Intralist and interlist effects in free recall. Psychological Review, 122(2), 337-363.

Long, N. M., \& Kahana, M. J. (2017). Modulation of task demands suggests that semantic processing interferes with the formation of episodic associations. Journal of Experimental Psychology: Learning, Memory, and Cognition, 43(2), 167-176.

Long, N. M., Danoff, M. S., \& Kahana, M. J. (2015). Recall dynamics reveal the retrieval of emotional context. Psychonomic Bulletin and Review, 22(5), 1328-1333.

May, C. P., Rahhal, T., Berry, E. M., \& Leighton, E. A. (2005). Aging, source memory, and emotion. Psychology and Aging, 20(4), 571.

McCluey, J. D., Burke, J. F., \& Polyn, S. M. (2018). Temporal and semantic structure of a study list alters temporal organization in free recall. Manuscript in preparation.

McDaniel, M. A., Cahill, M., Bugg, J. M., \& Meadow, N. G. (2011). Dissociative effects of orthographic distinctiveness in pure and mixed lists: An item-order account. Memory \& Cognition, 39(7), 1162-1173.

McGeoch, J. A. (1932). Forgetting and the law of disuse. Psychological Review, 39, 352-370. https://doi.org/10.1037/h0069819

Mensink, G.-J. M., \& Raaijmakers, J. G. W. (1988). A model for interference and forgetting. Psychological Review, 95, 434-455. https://doi.org/10.1037/0033-295X.95.4.434

Metcalfe, J., \& Murdock, B. B. (1981). An encoding and retrieval model of single-trial free recall. Journal of Verbal Learning and Verbal Behavior, 20, 161-189.

Miller, J. F., Kahana, M. J., \& Weidemann, C. T. (2012). Recall termination in free recall. Memory \& Cognition, 40(4), 540-550. https://doi.org/10.3758/s13421-011-0178-9

Miller, J. F., Lazarus, E., Polyn, S. M., \& Kahana, M. J. (2013). Spatial clustering during memory search. Journal of Experimental Psychology: Learning, Memory, and Cognition, 39(3), 773-781.

Moreton, B. J., \& Ward, G. (2010). Time scale similarity and longterm memory for autobiographical events. Psychonomic Bulletin and Review, 17(4), 510-515.

Murdock, B. B. (1962). The serial position effect of free recall. Journal of Experimental Psychology, 64, 482-488. https://doi.org/10. 1037/h0045106

Murdock, B. B. (1974). Human memory: Theory and data. Lawrence Erlbaum and Associates: Potomac.

Murdock, B. B. (1997). Context and mediators in a theory of distributed associative memory (TODAM2). Psychological Review, 104, 839-862. https://doi.org/10.1037/0033-295X.104.4.839
Murdock, B. B., \& Walker, K. D. (1969). Modality effects in free recall. Journal of Verbal Learning and Verbal Behavior, 8, 665676.

Murty, V. P., McKinney, R. A., DuBrow, S., Jalbrzikowski, M., Haas, G. L., \& Luna, B. (2018). Differential patterns of contextual organization of memory in first-episode psychosis. NPJ schizophrenia, 4(1), 3 .

Nairne, J. S. (1991). Positional uncertainty in long-term memory. Memory \& Cognition, 19(4), 332-340.

Nairne, J. S., Cogdill, M., \& Lehman, M. (2017). Adaptive memory: Temporal, semantic, and rating-based clustering following survival processing. Journal of Memory and Language, 93, 304314.

Nairne, J. S., \& Pandeirada, J. N. S. (in press). Adaptive memory: The evolutionary significance of survival processing. Perspectives on Psychological Science.

Nairne, J. S., Thompson, S. R., \& Pandeirada, J. N. (2007). Adaptive memory: Survival processing enhances retention. Journal of Experimental Psychology: Learning, Memory, and Cognition, 33(2), 263.

Nguyen, K., \& McDaniel, M. A. (2015). The picture complexity effect: Another list composition paradox. Journal of Experimental Psychology: Learning, Memory, and Cognition, 41(4), 1026.

Nielson, D. M., Smith, T. A., Sreekumar, V., Dennis, S., \& Sederberg, P. B. (2015). Human hippocampus represents space and time during retrieval of real-world memories. Proceedings of the National Academy of Sciences, 112(35), 11078-11083.

Oberauer, K., Lewandowsky, S., Farrell, S., Jarrold, C., \& Greaves, M. (2012). Modeling working memory: An interference model of complex span. Psychonomic Bulletin and Review, 19(5), 779?819.

Osth, A. F., \& Dennis, S. (2015). The fill-in effect in serial recall can be obscured by omission errors. Journal of Experimental Psychology: Learning, Memory, and Cognition, 41, 1447-1455.

Pajkossy, P., Keresztes, A., \& Racsmány, M. (2017). The interplay of trait worry and trait anxiety in determining episodic retrieval: The role of cognitive control. The Quarterly Journal of Experimental Psychology, 70(11), 2234-2250.

Phillips, J. L., Shiffrin, R. J., \& Atkinson, R. C. (1967). The effects of list length on short-term memory. Journal of Verbal Learning and Verbal Behavior, 6, 303-311.

Polyn, S. M., Norman, K. A., \& Kahana, M. J. (2009). A context maintenance and retrieval model of organizational processes in free recall. Psychological Review, 116, 129-156. https://doi.org/ $10.1037 / \mathrm{a} 0014420$

Polyn, S. M., Erlikhman, G., \& Kahana, M. J. (2011). Semantic cuing and the scale-insensitivity of recency and contiguity. Journal Experimental Psychology: Learning, Memory and Cognition, 37(3), 766-775.

Polyn, S. M., McCluey, J. D., Morton, N. W., Woolard, A. A., Luksik, A. S., \& Heckers, S. (2015). Temporal context and the organisational impairment of memory search in schizophrenia. Cognitive Neuropsychiatry, 20(4), 296-310.

Postman, L. (1971). Organization and interference. Psychological Review, 78(4), 290-302.

Postman, L. (1972). The experimental analysis of verbal learning and memory: Evolution and innovation. In Duncan, C. P., Sechrest, L., \& Melton, A. W. (Eds.) Human memory: Festschrift in honor of Benton J Underwood. New York: Appleton Century Crofts.

Primoff, E. (1938). Backward and forward associations as an organizing act in serial and in paired-associate learning. Journal of Psychology, 5, 375-395.

Raaijmakers, J. G. W., \& Shiffrin, R. M. (1981). Search of associative memory. Psychological Review, 88, 93-134. https://doi.org/10. 1037/0033-295X.88.2.93 
Sadeh, T., Moran, R., \& Goshen-Gottstein, Y. (2015). When items 'pop into mind': Variability in temporal-context reinstatement in free-recall. Psychonomic Bulletin \& Review, 22(3), 779-790.

Sahakyan, L., \& Kwapil, T. R. (2018). Moving beyond summary scores: Decomposing free recall performance to understand episodic memory deficits in schizotypy. Journal of Experimental Psychology: General, Advance online publication.

Schwartz, G., Howard, M. W., Jing, B., \& Kahana, M. J. (2005). Shadows of the past: Temporal retrieval effects in recognition memory. Psychological Science, 16, 898-904. https://doi.org/10. 1111/j.1467-9280.2005.01634.x

Sederberg, P. B., Miller, J. F., Howard, W. H., \& Kahana, M. J. (2010). The temporal contiguity effect predicts episodic memory performance. Memory and Cognition, 38(6), 689-699. https://doi.org/10.3758/MC.38.6.689

Shankar, K. H., \& Howard, M. W. (2012). A scale-invariant internal representation of time. Neural Computation, 24, 134-193. https://doi.org/10.1162/NECO_a_00212

Siddiqui, A. P., \& Unsworth, N. (2011). Investigating the role of emotion during the search process in free recall. Memory \& Cognition, 39(8), 1387-1400.

Solway, A., Murdock, B. B., \& Kahana, M. J. (2012). Positional and temporal clustering in serial order memory. Memory \& Cognition, 40(2), 177-190.

Spillers, G. J., \& Unsworth, N. (2011). Variation in working memory capacity and temporal-contextual retrieval from episodic memory. Journal Experimental Psychology: Learning, Memory and Cognition, 37(6), 1532-1539.

Spurgeon, J., Ward, G., \& Matthews, W. J. (2014). Examining the relationship between immediate serial recall and immediate free recall: Common effects of phonological loop variables but only limited evidence for the phonological loop. Journal of Experimental Psychology: Learning, Memory, and Cognition, 40(4), 1110.

Spurgeon, J., Ward, G., Matthews, W. J., \& Farrell, S. (2015). Can the effects of temporal grouping explain the similarities and differences between free recall and serial recall? Memory \& Cognition, 43(3), 469-488.

Stefanidi, A., \& Brewer, G. A. (2015). The recall dynamics of importance in delayed free recall (Unpublished master's thesis). Arizona State University.

Stefanidi, A., Ellis, D. M., \& Brewer, G. A. (2018). Free recall dynamics in value-directed remembering. Journal of Memory and Language, 100, 18-31.

Steyvers, M., Shiffrin, R. M., \& Nelson, D. L. (2004). Word association spaces for predicting semantic similarity effects in episodic memory. In Healy, A. F. (Ed.) Cognitive psychology and its applications: Festschrift in honor of Lyle Bourne, Walter Kintsch, and Thomas Landauer. Washington, DC: American Psychological Association.
Tulving, E. (1972). Episodic and semantic memory. In Tulving, E., \& Donaldson, W. (Eds.) Organization of memory, (pp. 381-403). New York: Academic Press.

Uitvlugt, M. G., \& Healey, M. K. (in press). Temporal proximity links unrelated news events in memory. Psychological Science.

Underwood, B. J. (1945). The effect of successive interpolations and proactive inhibition. Psychological Monographs, 59, 1-33. https://doi.org/10.1037/h0093547

Unsworth, N. (2008). Exploring the retrieval dynamics of delayed and final free recall: Further evidence for temporal-contextual search. Journal of Memory and Language, 59, 223-236. https://doi.org/10.1016/j.jml.2008.04.002

Unsworth, N. (2016). Working memory capacity and recall from longterm memory: Examining the influences of encoding strategies, study time allocation, search efficiency, and monitoring abilities. Journal of Experimental Psychology: Learning Memory and Cognition, 42, 50-61.

Unsworth, N., \& Brewer, G. (2010). Variation in working memory capacity and intrusions: Differences in generation or editing? European Journal of Cognitive Psychology, 22(6), 990-1000. https://doi.org/10.1080/09541440903175086

Unsworth, N., Brewer, G., \& Spillers, G. (2009). There's more to the working memory capacity-fluid intelligence relationship than just secondary memory. Psychonomic Bulletin and Review, 16(5), 931-937.

Wahlheim, C. N., \& Huff, M. J. (2015). Age differences in the focus of retrieval: Evidence from dual-list free recall. Psychology and Aging, 30(4), 768.

Wahlheim, C. N., \& Jacoby, L. L. (2013). Remembering change: The critical role of recursive remindings in proactive effects of memory. Memory \& Cognition, 41(1), 1-15.

Wahlheim, C. N., Ball, B. H., \& Richmond, L. L. (2017). Adult age differences in production and monitoring in dual-list free recall. Psychology and Aging, 32(4), 338-353.

Ward, G., Woodward, G., Stevens, A., \& Stinson, C. (2003). Using overt rehearsals to explain word frequency effects in free recall. Journal of Experimental Psychology: Learning, Memory, and Cognition, 29, 186-210.

Ward, G., Tan, L., \& Grenfell-Essam, R. (2010). Examining the relationship between free recall and immediate serial recall: The effects of list length and output order. Journal of Experimental Psychology: Learning, Memory, and Cognition, 36(5), 12071241.

Wechsler, D. (2008). Wechsler adult intelligence scale, (4th ed.). San Antonio: Pearson.

Zaromb, F. M., Howard, M. W., Dolan, E. D., Sirotin, Y. B., Tully, M., Wingfield, A., \& Kahana, M. J. (2006). Temporal associations and prior-list intrusions in free recall. Journal of Experimental Psychology: Learning, Memory, and Cognition, 32(4), 792-804. https://doi.org/10.1037/0278-7393.32.4.792 